On the Economic Determinants of

Free Trade Agreements

\author{
Scott L. Baier \\ Jeffrey Bergstrand
}

Working Paper \#290 - January 2002 


\title{
On the Economic Determinants of Free Trade Agreements
}

\author{
Scott L. Baier \\ Jeffrey Bergstrand
}

Working Paper \#290 - January 2002

Scott L. Baier is assistant professor of economics in the Jolen Walker Department of Economics at Clemson University. He teaches courses in macroeconomics and international economics. His research on macroeconomics and international trade has been published in the Journal of International Economics, Journal of Economic Dynamics and Control, and several other journals and books.

Jeffrey Bergstrand is associate professor of finance and business economics and $1^{\text {st }}$ Source Bank Faculty Fellow in the Mendoza College of Business, and a Fellow of the Helen Kellogg Institute at the University of Notre Dame. He teaches courses in macroeconomics, microeconomics, and international finance, and has received Outstanding Teaching Awards in the MBA program. His research on exchange rates, international trade flows, international finance, and open-economy macroeconomics has been published in American Economic Review, Economic Journal, Review of Economics and Statistics, Journal of International Economics, Journal of International Money and Finance, and in several other journals and books. Other publications include The Changing Distribution of Income in an Open US Economy (coeditor; 1994, North Holland Publishing) and Going Global: 25 Keys to International Operations (1999, New York Times Pocket MBA Series). He is the coeditor of the Review of International Economics. 


\begin{abstract}
The purpose of this study is to provide the first systematic empirical analysis of the economic determinants of the formation of free trade agreements (FTAs) and of the likelihood of FTAs between pairs of countries using a qualitative choice model. We develop this econometric model based upon a general equilibrium theoretical model of world trade with two factors of production, two monopolistically competitive product markets, and explicit intercontinental and intracontinental transportation costs among multiple countries on multiple continents. The empirical model correctly predicts, based solely upon economic characteristics, 83 percent of the 289 FTAs existing in 1996 among 1,431 pairs of countries and 97 percent of the remaining 1,142 pairs with no FTAs.
\end{abstract}

\title{
RESUMEN
}

El propósito de este estudio es proveer el primer análisis empírico sistemático de los determinantes económicos de la formación de acuerdos de libre comercio (ALC) y de la probabilidad de que se suscriban ALC entre pares de países utilizando un modelo cualitativo de elección. Desarrollamos este modelo econométrico basado en un modelo teórico de equilibrio general del comercio mundial con dos factores de producción, dos mercados de productos monopolítiscamente competitivos y explícitos costos de transporte inter e intracontinentales entre múltiples países en múltiples continentes. El modelo empírico predice correctamente, basándose solamente en características económicas, el 83\% de los 289 ALC existentes en 1996 entre 1431 pares de países y el 97\% de los restantes 1142 pares de países sin ALC. 

Free trade areas may well be an endogenous variable-that is, a response to, rather than a source of, large trade flows... Presumably, [governments] are more likely to form free trade areas, since the benefits outweigh the costs (Lawrence 1998, 59).

Ever since Viner (1950), international economists have debated whether or not free trade agreements—on net—enhance or reduce economic agents' welfare. For a half century, free trade agreements (FTAs) have been accepted if the anticipated trade "creation" exceeds the anticipated trade "diversion" for the members. In Vinerian terms, the formation of an FTA between two countries that leaves tariffs against other countries unchanged, could be beneficial or harmful to either country.

While most of the literature has focused on the welfare gains or losses from FTAs for member (and nonmember) countries, there is no study in the literature that has tried to explain —or predict-FTAs between pairs of countries, in the spirit of Lawrence's quote. As the quote above notes, FTAs may well be an endogenous variable. Lawrence's remark, in fact, should come as no surprise to trade economists, as there is a large literature in international economics on endogenous trade policy. As Trefler (1993) notes:

Trade theorists continue to puzzle over their surprisingly small estimates of the impact of trade liberalization on imports. All explanations of the puzzle...treat trade liberalization as a given. But the level of trade protection is not exogenous (138).

While a large literature exists explaining tariffs and nontariff barriers cross-sectionally, there is no study that has attempted to analyze econometrically the cross-sectional determinants of FTAs - much less one based upon a formal economic model. The goal of this paper is to determine the economic factors influencing the likelihood of pairs of countries forming FTAs in a given year, based upon a qualitative choice methodology. We hope to provide an empirical benchmark for the determinants of FTAs, upon which strategic and political factors can subsequently be embedded. Qualitative choice, or 
quantal response, models were designed to provide economists with the ability to evaluate decision-making behavior when choices are discrete (e.g., voting "yes" or "no") and characteristics of the population are unobservable (e.g., utility gain or loss from a policy decision). The decision to form an FTA is essentially a binary choice by a pair of countries' governments since, according to the GATT's Article XXIV, only complete (not partial) FTAs can be formed between pairs of countries. As McFadden (1975) noted, "Governments... are often given the general mandate to maximize public welfare" (401). Qualitative choice models provide a framework to estimate the probability that a pair of countries' governments are making a decision as if maximizing their respective agents' utilities in the absence of observations of utility. Such models provide "a ready interpretation of the selection probabilities in terms of the relative representative utilities of alternatives" (McFadden 1974, 112). This framework allows us to determine whether the economic characteristics identified in the theoretical model influence these probabilities empirically.

Trade-creating and trade-diverting economic characteristics of two countries' representative consumers do matter in explaining the probability of an FTA between their governments. Pairs of countries with FTAs tend to have the particular economic characteristics that the theory suggests should enhance the two countries' net trade creation and welfare (although possibly reducing the nonmembers' net welfare). We find strong evidence that pairs of countries' governments tend to form FTAs: (i) the closer two countries are geographically (more trade creation); (ii) the more remote a pair of natural trading partners is from the rest of the world (ROW) (less trade diversion); (iii) the larger and more similar in economic size are two trading partners (more trade creation); (iv) the greater the difference of capital-labor ratios between two trading partners (more trade creation); and (v) the smaller the difference of the members' capital- 
labor ratios with respect to the ROW's capital-labor ratio (less trade diversion). In the case of our framework, these pure economic characteristics can accurately predict 83 percent of the 289 FTAs existing among 1,431 country pairings in 1996 for which data were available and 97 percent of the remaining 1,142 pairs of countries with no FTAs.

This paper is arranged in seven sections. Section I analyzes the differences between the literatures on the "pure economics" of FTAs and on the "political economy" of FTAs. Section II presents the theoretical model. Section III discusses simulations, demonstrating theoretical relationships between the utility changes from an FTA and intercontinental transport costs, intracontinental transport costs, average levels of and differences between countries' real GDPs, and differences in relative factor endowments. Section IV discusses the econometric methodology and data requirements. Section V presents the empirical results and an evaluation of their robustness. Section VI interprets the results. Section VII concludes.

\section{Motivation and Related Literature}

The pure economic theory of trading blocs is essentially part of the broader theory of preferential trading arrangements. This theory...is a subject of inherent complexity and ambiguity; theory per se identifies the main forces at work, but offers few presumptions about what is likely to happen in practice. To make any headway, one must either get into detailed empirical work, or make strategic simplifications and stylizations that one hopes do not lead one too far astray. Obviously detailed empirical work is the right direction...(Krugman 1993, 60).

Krugman (1991b) delineated sharply for the 1990s the debate on the relative merits of regional FTAs. In that paper, he appropriately separated discussions of the "economics of trading blocs" and the "political economy of FTAs." In the 1990s, the debate about regional FTAs has subsequently followed these two tracks. For instance, the literature on the "economics of trading blocs" essentially addresses FTAs in a 
competitive framework, either perfect or monopolistic competition. In their Handbook of International Economics chapter "Regional Economic Integration," Baldwin and Venables (1995) similarly discuss the economics of FTAs in terms of competitive frameworks only; Baldwin and Venables' synthesis categorizes the approaches into firstgeneration (static perfect competition with constant returns to scale), second-generation (static monopolistic competition with increasing returns), and third-generation (dynamic competitive factor-accumulation) models. ${ }^{2}$ By contrast, Rodrik's (1995) chapter "Political Economy of Trade Policy" addresses political economy frameworks. We discuss each of these two approaches, but focus on the former.

As Baldwin and Venables (1995) note, the original analysis of the relative economic merits of trading blocs is attributed to Viner (1950), who addressed trade creation versus trade diversion within a perfectly competitive industry. The ambiguous relative merits of an FTA were derived in a setting with no transport costs and unchanged tariffs of bloc members on nonbloc trading partners, and led to a voluminous literature interpreting his analysis. The ambiguous welfare effects from an FTA apply to member and nonmember countries.

In addressing the economics of FTAs, Krugman (1991a,b) addressed the relative merits of FTAs in a static monopolistically competitive framework, similar to the "core" second-generation models discussed in Baldwin and Venables, but recognized economic geography. With zero intercontinental transport costs, continental FTAs decrease welfare unambiguously. With prohibitive intercontinental transport costs, such agreements increase welfare unambiguously, leaving the results contingent upon the degree of transportability of goods.

Krugman (1991b) concluded that "despite the potential for trade diversion" because most FTAs are among "natural" trading partners, the likelihood of much trade 
diversion was small and "prospective moves toward regional free trade would almost surely do more good than harm to the members of the free trade areas" (21). However, in his subsequent commentary, Bergsten (1991) noted: “This is an empirical question on which Krugman offers little supportive evidence" (48). It is our goal to provide supportive evidence here.

The resulting debate led Frankel (1997) and Frankel, Stein, and Wei (henceforth, FSW) $(1995,1996,1998)$ to distinguish between natural, unnatural, and supernatural FTAs. First, as shown in Figure 1, for high intercontinental transport costs $(b>0.15)$ FTAs between countries that are geographically close-natural FTAs-are welfare enhancing and should lead social planners in these countries to adopt FTAs, because large intracontinental trade creation would dominate small intercontinental trade diversion as intracontinental (intercontinental) transport costs are zero (positive). Second, for any level of intercontinental transport costs, FTAs between countries geographically distant-unnatural FTAs_-are welfare decreasing and should lead countries' social planners to avoid FTAs, as the welfare loss from intracontinental trade diversion exceeds the welfare gain from intercontinental trade creation. Third, for low intercontinental transport costs $(b<0.15)$, FTAs between countries geographically close-denoted supernatural FTAs by FSW-are welfare reducing and should lead social planners in these countries to avoid FTAs, because intracontinental trade creation would be dominated by intercontinental trade diversion.

In the context of a qualitative choice framework with social planners, the FSW analysis and its implications suggest two hypotheses. First, other things being constant, the more natural (i.e., closer) are two trading partners, the more likely an FTA will be formed by the countries' governments due to more potential trade creation. Second, the 
more remote from the rest of the world are continental trading partners (i.e., the larger are intercontinental transport costs), the more likely an FTA will be formed due to less potential trade diversion. Consequently, the FSW model suggests two potential economic factors that could predict FTAs: the distance between two countries and the remoteness of two (continental) trading partners. ${ }^{3}$

In reality, however, the world is not so generous as to make all countries identical in terms of economic size or relative factor endowments, nor are intracontinental transport costs zero. First, as noted in comments on FSW (1998) by Krugman (1998), the restriction of identical economic sizes may not be innocuous:

My second, more analytical, concern is with the way Frankel, Stein, and Wei map the theoretical model onto the real world...there is a crucial assumption in the model that is not nearly true of the real world: that countries themselves are of equal economic size. In reality, of course, the size distribution of GDPs is highly unequal, and this surely makes a major difference when we try to model the effects of integration (115).

Second, the models in Krugman and FSW assume a world with one factor and one industry. As noted in Deardorff and Stern (1994) and Haveman (1996), such a model precludes trade in traditional comparative advantages, such as Heckscher-Ohlin trade. By eliminating traditional comparative advantages, the model may be relying too heavily on imperfect substitution among products that "stacks the cards" against bilateralism (Deardorff and Stern 1994, 56).

Third, the Krugman and FSW models assume intracontinental transport costs are zero. Just as FSW noted Krugman's conclusions are sensitive to intercontinental transport costs, Nitsch (1996) challenged the FSW work by noting that the results are sensitive to intracontinental transport costs. Nitsch argued that introducing an intracontinental transport cost may cause the FSW phenomenon of "supernatural" FTAs to "disappear." The intuition behind this is that the net benefits of a continental FTA are due to the 
relationship of intercontinental transport costs relative to intracontinental costs. In FSW, the assumption of zero intracontinental transport costs is not innocuous; the trade diversion effect on welfare of a continental FTA is enhanced with zero intracontinental transport costs.

We generalize the Krugman-FSW model here to allow for economies with different absolute and relative factor endowments, and intra- as well as intercontinental transport costs. In our framework, governments are assumed to maximize their citizens' economic welfare. The net welfare gain or loss of two countries from forming an FTA depends on the trade creation versus trade diversion of the members. The economic determinants of trade creation and trade diversion can be categorized into three groups. The first group consists of economic geography factors. Other things being equal, trade creation will be greater the closer two countries are to each other, and trade diversion will be less the more remote two (natural) trading partners are from the ROW. The second category is intraindustry trade determinants. Trade creation will be greater the larger and more similar two countries are in economic size, and trade diversion will be less the smaller the economic size of the ROW. The third category is interindustry (or HeckscherOhlin) trade determinants. Trade creation will be greater the wider relative factor endowments are between two countries, and trade diversion will be less the smaller the difference between the relative factor endowments of the pair and that of the ROW.

Finally, because we are introducing an alternative approach toward assessing FTAs, we must briefly discuss the issues that we are not addressing in order to make our analysis tractable and to limit the paper's scope and length. First, as noted earlier, the alternative track to the literature on the "pure economics" of FTAs is the literature on the "political economy" of FTAs. The latter literature is concerned largely with explaining 
theoretically the level of trade liberalization in general, or an FTA in particular, based on the relevant economic actors in an imperfect market structure with little competition. As discussed in his Handbook of International Economics chapter, "Political Economy of Trade Policy," Rodrik (1995) notes that these models are quite distinct from the competitive structures discussed earlier either because, as in Grossman and Helpman (1995), ownership of specific factors is assumed to be highly concentrated among a few firms, or because the government has a preference for a certain distributional outcome that differs from that of the social planner. In the absence of special interest lobbies or certain government distributional preferences, a country's government would act as a social planner, maximizing the welfare of the country's representative household.

Empirical investigations in the political economy literature of the determinants of endogenous tariff and nontariff barriers across industries and countries abound. However, as Rodrik (1995) notes, the standard approach has been to regress some measure of protection on a number of economic and political variables. He adds that "the links between the empirical and theoretical have never been too strong in this area" (1480). To our knowledge, Goldberg and Maggi (1999) and Gawande and Bandyopadhyay (2000) are the only empirical studies in the political economy literature on determinants of trade protection based upon an explicit theoretical model.

As this paper is the first to attempt to explain empirically the determinants of FTAs, we choose here to assume a social planner for each country that maximizes the welfare of its consumers. While in reality political lobbies and government distributional preferences may well influence FTA decisions, we choose intentionally to ignore these factors to limit the scope and enhance the tractability of our analysis. We find empirical support for our approach in Goldberg and Maggi (1999), who found that "the weight of [consumer economic] welfare in the government's objective function is many times 
larger than the weight of [political] contributions" (1135; italics added). Specifically, they estimated the weight of consumer welfare (political contributions) in government trade policy decisions to be 98 percent ( 2 percent). Our empirical investigation of select economic determinants of FTAs, based upon a general equilibrium model with monopolistically competitive firms and a social planner maximizing consumer welfare, consequently potentially complements the political economy literature on empirical determinants of trade protection (where governments weigh consumer welfare, lobbying interests, and distributional preferences). Our paper is designed to develop an empirical "benchmark" for pure economic factors; we hope that future research will address empirically political economy factors influencing FTA formations.

Second, we assume that the decision for a pair of countries' governments to form an FTA is based upon the welfare of the representative agents of the country pair, and ignore the possible net welfare loss to nonmember countries. We assume a social planner for each country, not for the world. In the (more restrictive) symmetric models of Krugman and FSW, inferences could be made about world welfare, and whether FTAs were good or bad for the world. We cannot attempt to address world welfare empirically; we restrict our analysis to the net welfare gain or loss of trade creation versus trade diversion for member countries. ${ }^{4}$ As noted in Baldwin and Venables (1995), the tension between trade creation versus trade diversion makes the net welfare gain ambiguous for nonmember and member countries. ${ }^{5}$

Third, we treat the decision to enter an FTA as bilateral, rather than multilateral. While the decision to form an FTA with the European Union (EU), for instance, may appear to be a multilateral one, every country in the EU has the ability to veto an FTA. In 
effect, every country in the EU decides bilaterally whether the net national welfare gain from an FTA with another country warrants formation. ${ }^{6}$

Fourth, as we are interested in explaining empirically the cross-sectional variation in FTAs for a given year (1996), we assume that each country pair makes a decision in 1996 to form or not form an FTA, or to enforce or not enforce an FTA formed prior to 1996. This "static" approach is in conformity with most cross-sectional "gravity" analyses of bilateral trade flows where the presence or absence of an FTA is determined exogenously and annually based upon government documentation. Thus, the underlying theory, as in Krugman and FSW, is static. In theory, the presence or absence of an FTA in a given year depends only upon the economic characteristics in that year (thus precluding dynamic factors, such as existing FTAs, etc.), similar to empirical endogenous cross-sectional trade policy studies such as Lee and Swagel (1997), Goldberg and Maggi (1999), and Gawande and Bandyopadhyay (2000); dynamic issues are important, but are outside the scope of the present paper and are left for future research.

\section{The Model}

In the spirit of the Krugman-FSW frameworks, international trade within each of two monopolistically competitive sectors is generated by the interaction of consumers having tastes for diversity and production being characterized by economies of scale. We assume two factors of production, capital and labor, each perfectly mobile between sectors and each immobile internationally. We label the two sectors goods and services. However, we stress that, initially, these labels are arbitrary. Only much later in the analysis will we differentiate the two sectors along conventional Balassa-Samuelson lines: goods (services) will be capital (labor) intensive in production and more (less) tradable. The monopolistic-competition framework is standard in modeling international 
trade in goods (e.g., manufactures) in the context of the new trade theory. ${ }^{7}$ Within each sector, a taste for diversity exists, captured formally by Dixit-Stiglitz preferences. Increasing returns to scale internal to the firm are captured with fixed costs and linear cost functions.

To capture the effects of asymmetries on regionalism, we assume three continents (indexed by 1, 2, 3) with two countries on each continent (indexed by A and B). Each country is allowed potentially to have different absolute and relative factor endowments of capital and labor. The two sectors are allowed potentially to differ in terms of relative factor intensities, tastes for variety, and trade barriers (transportation costs and/or tariffs). While earlier computable general equilibrium models address the relative welfare benefits of regionalism versus multilateralism, they do not explore these effects with explicit intercontinental and intracontinental transport costs, recognizing-in the spirit of the Krugman and FSW frameworks-world geography. ${ }^{8}$

\section{A. Consumers}

Each country has a representative consumer who derives utility from consuming goods and services ( $g$ and $s$, respectively) based upon Cobb-Douglas preferences. Within each sector, the consumer has a taste for diversity captured formally by Dixit-Stiglitz

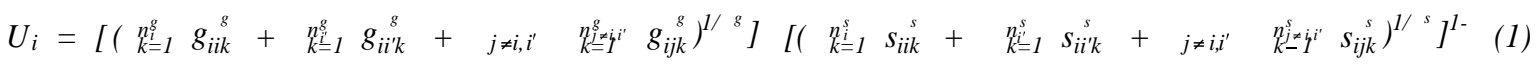

preferences. Thus, the representative consumer for each of the six countries $(i=1 \mathrm{~A}, 1 \mathrm{~B}$, $2 \mathrm{~A}, 2 \mathrm{~B}, 3 \mathrm{~A}, 3 \mathrm{~B})$ has a nested utility function, where $\mathrm{U}_{i}$ denotes the utility of the representative household in country $i$. Where $g_{i i k}$ is consumption in country $i$ of (differentiated) good $k$ produced in the home country $(i), g_{i i^{\prime} k}$ is consumption in country $i$ of good $k$ produced in the foreign country on the same continent $\left(i^{\prime}\right)$, and $g_{i j k}$ is 
consumption in country $i$ of good $k$ produced in each of the four foreign countries on other continents $\left(j \neq i, i^{i}\right)$. Similarly, where $s_{i i k}$ is consumption of (differentiated) service $k$ produced in the home country, $s_{i i^{\prime} k}$ is consumption of service $k$ produced in the foreign country on the same continent, and $s_{i j k}$ is consumption of service $k$ produced in each of the four foreign countries on other continents. Let $\theta^{g}\left(\theta^{s}\right)$ denote the parameter determining the elasticity of substitution in consumption in goods (services) with $0<\theta^{\text {g }}$, $\left(\theta^{\mathrm{s}}\right)<1$. Let $\gamma(1-\gamma)$ be the Cobb-Douglas preference parameter for goods (services). Finally, where $n_{i}^{g}\left(n_{i}^{s}\right)$ is the number of varieties of goods (services) produced in the home country, $n_{i}{ }^{g}\left(n_{i}{ }^{s}\right)$ is the number of varieties of goods (services) produced in the foreign country on the same continent, and $n_{j}^{g}\left(n_{j}^{s}\right)$ is the number of varieties of goods (services) produced by a foreign country on another continent.

Within any country, households and firms are assumed symmetric, hence, we may replace $\sum_{k=1}^{n_{\xi}^{g}}\left(\sum_{k=1}^{n_{i}^{s}}\right)$ by $n_{i}^{g}$ and $n_{i}^{s}$, respectively. Consequently, the budget constraint for the representative consumer in country $i$ is:

$w_{i}+r_{i}\left(K_{i} / L_{i}\right)+T_{i}=n_{i}^{g} p_{i}^{g} g_{i i}+n_{i^{\prime}}{ }^{g} p_{i i}{ }^{g} g_{i i}+\sum_{j \neq i, i} n_{j}^{g} p_{i j}^{g} g_{i j}+n_{i}^{s} p_{i}^{s} s_{i i}+n_{i}{ }^{s} p_{i i^{s}}{ }^{s} s_{i i}+\Sigma_{j \neq i, i} n_{j}^{s} p_{i j}^{s} s_{i j}$

where $w_{i}$ is the wage rate of the representative consumer-worker (or household) in country $i, r_{i}$ is the rental rate on capital per household, $K / L_{i}$ is the amount of capital exogenously supplied (or endowed) per household, $T_{i}$ is tariff revenue redistributed back to households in a lump sum, $p_{i}^{g}\left(p_{i}^{s}\right)$ is the price of the good (service) produced in the home country, $p_{i i}{ }^{g}\left(p_{i i}{ }^{s}\right)$ is the Cost-Insurance-Freight (c.i.f.) price of the good (service) produced in the foreign country on the same continent, and $p_{i j}{ }^{g}\left(p_{i j}{ }^{s}\right)$ is the c.i.f. price of the good (service) produced in a foreign country on another continent. Under symmetry within a country, subscript $k$ can be eliminated. 
Following FSW, c.i.f. prices differ from home prices due to Samuelson-type "iceberg" transportation costs and ad valorem tariffs. Let $a(b)$ represent the fraction of output exported by a country that is "consumed" (or lost) due to intra- (inter-) continental transport. ${ }^{9}$ Let $t_{i i}$ and $t_{i j}$ denote the ad valorem tariff rates in country $i$ (that can potentially differ by trading partner). In the presence of positive tariffs and transport costs, the price level of the good (service) of the foreign country on the same continent, $p_{i i i^{\prime}}\left(p_{i i}{ }^{s}\right)$, is:

$$
\begin{aligned}
& p_{i i}{ }^{g}=\left(p_{i}{ }^{g}\right)\left[1 /\left(1-a^{g}\right)\right]+p_{i},{ }^{g} t_{i i}{ }^{g} \\
& p_{i i}{ }^{s}=p_{i}{ }^{s}\left[1 /\left(1-a^{s}\right)\right]+p_{i}{ }^{s} t_{i i}{ }^{s},
\end{aligned}
$$

The price level of the good (service) of a foreign country on a different continent, $p_{i j}{ }^{g}$ $\left(p_{i j}{ }^{s}\right)$, is:

$$
\begin{aligned}
& p_{i j}^{g}=p_{j}^{g}\left\{1 /\left[\left(1-a^{g}\right)\left(1-b^{g}\right)\right]\right\}+p_{j}^{g} t_{i j}^{g} \\
& p_{i j}{ }^{s}=p_{j}^{s}\left\{1 /\left[\left(1-a^{s}\right)\left(1-b^{s}\right)\right]\right\}+p_{j}^{s} t_{i j}^{s}
\end{aligned}
$$

Tariff rates and transport costs are allowed to differ between sectors. ${ }^{10}$ For each country's consumer, maximizing (1) subject to equations (2), (3), and (4) yields a set of demand equations which, for brevity, are omitted here.

\section{B. Firms}

Each firm in the goods industry is assumed to produce output subject to the technology:

$$
g_{i}=z_{i}^{g}\left(k_{i}^{g}\right)^{\alpha g}\left(l_{i}^{g}\right)^{l-\alpha g}-\phi^{g}
$$


where $g_{i}$ denotes output of the representative firm, $z_{i}^{g}$ is an exogenous productivity term for goods producers, $k_{i}^{g}$ is the amount of capital used by the representative firm in country $i, l_{i}^{g}$ is the amount of labor used by the representative firm in $i$, and $\phi^{g}$ represents a fixed cost facing each firm (e.g., marketing costs absorbing both capital and labor), the latter assumed identical across countries for simplicity. Similarly, each firm in the services industry is assumed to produce output subject to the technology:

$$
s_{i}=z_{i}^{s}\left(k_{i}^{s}\right)^{\alpha s}\left(l_{i}^{s}\right)^{1-\alpha s}-\phi^{s}
$$

where $s_{i}$ denotes output of the representative firm, $z_{i}^{s}, k_{i}^{s}, l_{i}^{s}$, and $\phi^{s}$ are defined analogously for services, and factor intensities $\alpha^{\mathrm{g}}$ and $\alpha^{\mathrm{s}}$ can be allowed to differ.

Firms in each industry in each country maximize profits subject to the technology defined in equations (5) and (6), given the demand schedules implied by section A above. Equilibrium in these types of models is characterized by two conditions. First, profit maximization ensures that prices are a markup over marginal production costs:

$$
\begin{aligned}
& p_{i}^{g}=\left(\theta^{g}\right)^{-1}\left[\left(C / z_{i}^{g}\right) r_{i}^{\alpha g} w_{i}^{l-\alpha g}\right] \\
& p_{i}^{s}=\left(\theta^{s}\right)^{-1}\left[\left(D / z_{i}^{s}\right) r_{i}^{\alpha s} w_{i}^{l-\alpha s}\right]
\end{aligned}
$$

where $C=\left(\alpha^{g}\right)^{-\alpha \mathrm{g}}\left(1-\alpha^{\mathrm{g}}\right)^{-(1-\alpha \mathrm{g})}$ and $D=\left(\alpha^{\mathrm{s}}\right)^{-\alpha \mathrm{s}}\left(1-\alpha_{\mathrm{s}}\right)^{-(1-\alpha \mathrm{s})}$. Second, under monopolistic competition firms earn zero profits, which implies:

$$
\begin{aligned}
& g_{i}=\theta^{g} \phi^{g} /\left(1-\theta^{g}\right) \\
& s_{i}=\theta^{s} \phi^{s} /\left(1-\theta^{s}\right)
\end{aligned}
$$

As common to this class of models, output of the representative firm in each industry is determined parametrically. 


\section{Factor Endowment Constraints}

As is standard, we assume that endowments of capital $\left(K_{i}\right)$ and labor $\left(L_{i}\right)$ are exogenous, with both factors internationally immobile. Assuming full employment:

$$
\begin{aligned}
& K_{i}=K_{i}^{g}+K_{i}^{s}=n_{i}^{g} k_{i}^{g}+n_{i}^{s} k_{i}^{s} \\
& L_{i}=L_{i}^{g}+L_{i}^{s}=n_{i}^{g} l_{i}^{g}+n_{i}^{s} l_{i}^{s}
\end{aligned}
$$

\section{Equilibrium}

The number of firms and product varieties in each industry and country, factor employments and prices in each industry and country, consumptions of each good, and product prices can be determined uniquely given parameters of the model $\left(\gamma, \theta^{g}, \theta^{s}, \alpha^{\mathrm{g}}, \alpha^{\mathrm{s}}, \phi^{\mathrm{g}}, \phi^{\mathrm{s}}\right)$ and initial transport costs, tariffs, and factor endowments. All together, the model includes 204 equations in 204 endogenous variables (not all behavioral equations and identities shown here).

\section{E. The Social Planner}

As noted in Rodrik (1995), the political economy literature on endogenous trade policy typically assumes that the government weighs two factors in choosing the level of protection. One factor is the welfare of the representative consumer. The other factor is generally some measure of political influence. For example, in Grossman and Helpman (1994, 1995), Mitra (1999), and Goldberg and Maggi (1999), the government maximizes a weighted average of social welfare and political lobby contributions. In a competitive framework, the government reduces to a social planner and maximizes the representative consumer's welfare. Thus, if economic characteristics of a pair of countries' enhance 
welfare of the countries' representative consumers, then as noted by Lawrence in the introduction "such groups are more likely to form free trade areas, since the [welfare] benefits outweigh the [welfare] costs."

While the assumption that governments maximize consumers' welfare may seem unrealistic, Goldberg and Maggi (1999) estimated, using US data, the relative weights for social welfare and political contributions based upon the Grossman-Helpman model. In their study, the weight on the consumers' welfare was estimated to be between 0.98 and 0.99 depending on parameter values, suggesting that consumer welfare dominates political contributions in government trade policy decisions. ${ }^{11}$

In our analysis, the social planner in each country acts on behalf of the country's representative agent. Initially, the social planner can set the optimal tariff (assuming no FTAs are possible). ${ }^{12}$ If the changes in utility for two countries' agents from an FTA are positive, we assume each social planner would choose to enter an FTA with the other country's planner. Thus, for a bilateral FTA to be formed, it must be the case that the change in utility is positive for both countries' agents. If the change in utility is negative for either country, we assume an FTA is not formed.

\section{Theoretical Results}

This section has four parts and offers six theoretical hypotheses about the relationships between the net gains from an FTA and various economic characteristics of country pairs. Section A replicates two main results from FSW $(1995,1996,1998)$ and Frankel (1997) in the context of a symmetric world with zero intracontinental transport costs. Section B relaxes the assumption of zero intracontinental transport costs, and illustrates the complex theoretical relationships among intercontinental transport costs, intracontinental transport costs, and the net gains from an FTA; the assumption of zero 
intracontinental transport costs is not innocuous. Section $\mathrm{C}$ relaxes the assumption of symmetrically sized economies; we demonstrate the monotonic relationships between levels and similarities of economic size and the net gains from an FTA. Section D relaxes the assumption of only one industry and one factor; we demonstrate the potentially nonmonotonic theoretical relationship between relative factor endowment differences and the net gains from an FTA in a world with two industries, two factors, and transport costs.

\section{A. Replicating the Frankel-Stein-Wei (FSW) Model}

Two key implications from FSW $(1995,1996,1998)$ are that (1) natural FTAs are unambiguously welfare superior to unnatural FTAs and (2) the net welfare benefits from a natural FTA increase as the intercontinental transport costs of the good increase. The general implication is that-if a country's social planner is maximizing a representative consumer's utility-the planners are more likely to form an FTA: (1) the smaller the distance between two countries, and (2) the greater the distance between a pair of natural trading partners and the rest of the world (ROW).

The intuition underlying these two implications is related to the notions of trade creation and trade diversion. First, for a given distance between a pair of countries and the ROW, the closer the two countries (that is, the more "natural" two countries are as trading partners), the lower their transport costs of international trade. Consequently the trade creation will be greater from a natural FTA. ${ }^{13}$ This is the intuition behind the higher utility increase from a continental FTA relative to a noncontinental FTA. Second, for a given distance between two countries, the farther these countries are from the ROW, the higher their transport costs of international trade with the ROW and thus the less these 
two countries trade with the ROW. Hence, the trade diversion will be less from an FTA between the two countries. ${ }^{14}$

As a benchmark, we compare the case of perfect symmetry in goods and services in our model with the single-industry case in FSW. Consider initially a special case of our model where countries and continents are identical in terms of factor endowments $\left(K_{i}=L_{i}\right.$ $=100$ for $i=1 \mathrm{~A}, \ldots, 3 \mathrm{~B})$ and industries are identical in terms of transport costs, tastes, and trade, as in FSW. With perfect symmetry, tariff rates between sectors and countries $\left(t_{i i}{ }^{g}, t_{i j}{ }^{g}, t_{i i}{ }^{s}, t_{i j}{ }^{s}\right)$ are identical, transport costs between continents $\left(b^{g}, b^{s}\right)$ and between countries on the same continent $\left(a^{g}, a^{s}\right)$ are identical between sectors, factor intensities $\left(\alpha^{\mathrm{g}}, \alpha^{\mathrm{s}}\right)$ are identical, elasticities of substitution in consumption in goods and services (determined by $\theta^{g}$ and $\theta^{s}$ ) are identical, and the preferences for goods and services are identical $(\gamma=1-\gamma=1 / 2)$. For simplicity at this point, fixed costs in each sector $\left(\phi^{g}, \phi^{s}\right)$ are unity, tariff rates are 0.30 initially in both sectors as in FSW (see footnote 12), and in each sector total factor productivity is normalized to unity $\left(z_{i}^{g}=z_{i}^{s}=1\right)$.

First, if we consider the case in FSW where $\theta=0.75$ (implying an elasticity of substitution in consumption in each sector of four) and transport costs on the same continent $\left(a^{g}, a^{s}\right)$ are assumed zero, the relative welfare benefits from FTAs are identical to those in FSW (1995), as shown in Figure 1-identical to FSW's Figure 2. The top solid line represents the net gains or losses from a continental (regional) FTA-or "natural" FTA - in goods and services. The bottom solid line represents the net losses from an unnatural (noncontinental) FTA. As in FSW, the net welfare benefit from a natural FTA exceeds that from an unnatural FTA at any level of intercontinental transport costs.

Second, as in FSW, regional FTAs reduce welfare for an intercontinental transport cost factor, $b$, between 0 and 15 percent; a value of $b$ of 15 percent suggests a 
c.i.f.-f.o.b. (Cost-Insurance-Freight to Free-on-Board) factor of 18 percent $(b /[1-b])$. This important result from FSW led the authors to argue that regional FTAs may be welfare diminishing. At low intercontinental transport costs, the continental FTA leads to a large loss of consumption of varieties from other continents, creating extensive trade diversion for consumers. ${ }^{15}$ By contrast, at high intercontinental transport costs, a continental FTA is welfare improving because little trade exists between countries on different continents so trade creation of varieties between natural trading partners exceeds the trade diversion of varieties with unnatural partners.

Thus, the welfare gain from a natural FTA increases as intercontinental transport costs increase. Moreover, FSW show that the welfare loss from an unnatural FTA decreases as the intercontinental transport costs increase because there is little intercontinental trade. Thus, their model implies that the more remote pairs of countries are, the larger gains are from a natural FTA and the smaller the losses are from an unnatural FTA.

However, when both intercontinental and intracontinental transport costs are allowed to vary, we find that a monotonic theoretical relationship exists only between the net welfare benefit from a natural FTA and intercontinental transport costs. For certain intracontinental transport cost levels, the net welfare gain from an unnatural FTA may be a quadratic function - or even a negative function-of intercontinental transport costs.

\section{B. Extending the FSW Model: Asymmetric Inter- and Intracontinental Transport Costs}

A commonly overlooked assumption in this literature-presumably based on the notion that this assumption is innocuous-is that intracontinental transport costs are zero. In reality, of course, intracontinental transport costs are positive, and such an assumption 
might not be innocuous, as noted in Nitsch (1996). In reality, the relationship between intercontinental transport costs, intracontinental transport costs, and the welfare benefits from a regional FTA is more complex than that suggested by FSW or Nitsch.

First, Figure 2a is a three-dimensional representation of the relationship between intercontinental transport costs, intracontinental transport costs, and net benefits from either a natural FTA or an unnatural FTA. The top (bottom) surface is the net welfare gain from a natural (unnatural) FTA. Consistent with the two-dimensional case for $a=0$, the welfare effects of a natural FTA exceed (or equal) those of an unnatural FTA for any levels of inter- and intracontinental transport costs. Figure 1 is a special case of Figure $2 \mathrm{a}$, evaluated at $a=0$; this special case is shown in Figure 2a by the plane relating "\% Change in Welfare" to "Intercontinental T.C. Factor." Thus, the relationship identified in FSW is robust to varying intracontinental transport costs $(a){ }^{16}$

As it is difficult to show visually in Figure 2a the difference between the surfaces from every possible angle, Figure $2 \mathrm{~b}$ depicts net welfare gains from natural FTAs less net welfare gains from unnatural FTAs for every value of $a$ and $b$. This figure illustrates clearly that the net welfare gains are unambiguously larger (or zero) for natural relative to unnatural FTAs. The implication of this theoretical analysis is that two countries that are close in distance to one another-that is, are natural trading partners-will gain relatively more in welfare than two countries far apart. This suggests the first hypothesis:

Hypothesis 1: The net gain from an FTA between two countries increases as the distance between them decreases.

The second important implication from the FSW model and our Figure 1 is that the net welfare gains (losses) from a natural (unnatural) FTA increase (decrease) the 
greater are intercontinental transport costs $(b)$ relative to intracontinental transport costs (a). The intuition is essentially trade diversion. For a natural FTA, as intercontinental transport costs increase relative to intracontinental transport costs, there is less international trade with distant partners, reducing the trade diversion in the model. For an unnatural FTA, as $b$ increases relative to $a$ there is less international trade with unnatural partners, reducing the welfare loss from an unnatural FTA.

Figure 2a reveals clearly for any level of $a$ the monotonic relationship between greater intercontinental transport costs and the larger net welfare benefits from a natural FTA. One can see readily that the FSW model is a special case of our model. At $a=0$, the welfare effect of a regional FTA increases monotonically with $b$, and replicates (in the left-hand-side plane at $a=0$ ) Figure 1's two-dimensional top line.

At higher values of $a$, the shape of this relationship remains monotonic, but "flattens" considerably. The intuition is the following. First, suppose $b$ is very low. If $a$ is zero, then the intercontinental trade diversion from a continental FTA exceeds the intracontinental trade creation; with $a$ equal to zero, there is no cost to transport goods intracontinentally. Yet with low $b$, a continental FTA causes the loss of consumption of varieties from other continents (trade diversion) to be large and to exceed the trade creation intracontinentally. However, at high levels of $a$, there is relatively little international trade, and the net welfare loss from trade diversion diminishes.

Next, suppose $b$ is very high. Even if $a$ is zero, there is little intercontinental and much intracontinental trade, and hence little intercontinental trade diversion from a continental FTA. If $a$ increases, intracontinental trade creation is dampened, decreasing the welfare gains from a continental FTA. Thus, the relationship between $b$ and welfare from a continental FTA flattens as $a$ increases. ${ }^{17}$ 
Figure 2a shows clearly that-for two natural trading countries- the net welfare benefits from FTAs increase as intercontinental transport costs increase for any given value of $a$. This implies that-for any two natural trading countries-the net welfare benefit from an FTA increases as the distance of this pair of countries from the ROW rises. This suggests a second empirically testable hypothesis.

However, Figure 2a does not show clearly the relationships between intercontinental transport costs, intracontinental transport costs, and the welfare effects of an unnatural FTA. Figure 3 illustrates that the three-dimensional relationship between these factors is more complex. First, the plane with axes labeled "\% Change in Welfare" and "Intercontinental T.C. Factor" at $a=0$ replicates the special (two-dimensional) case in FSW, represented by the bottom line in Figure 1. FTAs between countries on different continents result in a welfare loss, and the loss increases as intercontinental transport costs fall. At higher intercontinental transport costs, there is little intercontinental trade so unnatural FTAs will have little effect on trade or welfare. However, as intercontinental transport costs fall, unnatural FTAs lead to significant trade diversion vis-à-vis other countries on the same or different continents, rather than offsetting any trade creation.

Figure 3 shows that the relationship between intercontinental transport costs and the welfare effects changes as intracontinental transport costs increase; hence, the assumption of zero intracontinental transport costs in the Krugman and FSW models is not innocuous. For instance, at a value of $a=0$, the relationship is monotonic and positive (for increasing $b$ ); at $a=0.2$, the relationship is quadratic; at $a=0.4$, the relationship is monotonic and negative. The complexity of the relationships can be appreciated by evaluating the welfare effects from unnatural FTAs as $a$ increases, assuming, for instance, intercontinental transport costs $(b)$ are low. The welfare loss of unnatural FTAs is greatest when $a$ is small. As $a$ rises, the welfare loss of unnatural FTAs 
is reduced because there is less trade diversion from natural trading partners (because with higher $a$, there is less intracontinental trade). As $a$ rises (say, to 0.4), the loss in welfare from trade diversion intracontinentally is more than offset by the trade creation within the unnatural blocs (because $a$ is rising relative to $b$ ), so that-on net-welfare rises. ${ }^{18}$ Beyond $a=0.4$, however, the costs of transporting goods intracontinentally become so prohibitive, unnatural FTAs have no effect on welfare due to little international trade.

Thus, the relationship between welfare changes and intercontinental transport costs are influenced by intracontinental transport cost levels. A generalization of the Krugman and FSW models to allow variable inter- and intra-continental transport costs suggests that the relationship between such costs and the welfare effects of unnatural FTAs is more complex than the earlier models implied. ${ }^{19}$ The complexity precludes a potentially testable hypothesis concerning remoteness for unnatural partners. Consequently, the hypothesis from this section applies to natural FTAs:

Hypothesis 2: The net welfare gain from an FTA for two natural trading partners increases as their remoteness from the ROW increases.

\section{Asymmetric Country Sizes}

Up to this point, countries have been symmetric in economic characteristics. In this section, we introduce asymmetric country sizes in terms of absolute factor endowments to determine scale-economies effects. Our extension of the FSW model to introduce different absolute factor endowments, and consequently different real GDP levels, addresses the concerns raised earlier in Krugman (1998). To show that the relationship between the net welfare gain from an FTA and economic size is qualitatively 
independent of transport costs, we examine this in two exercises, the first for natural trading partners and the second for unnatural partners. In the first exercise, we allow countries on continent $1(1 \mathrm{~A}, 1 \mathrm{~B})$ to have larger absolute endowments of capital and labor than countries on continent $2(2 \mathrm{~A}, 2 \mathrm{~B})$, and countries $2 \mathrm{~A}$ and $2 \mathrm{~B}$ to have larger absolute endowments than countries on continent 3 (3A, 3B). Countries on the same continent have identical factor endowments. Moreover, for now, relative factor endowments (capital-labor ratios) in every country are identical.

Intuitively, the welfare gains from natural FTAs should be higher for the countries with larger absolute factor endowments (and consequently larger real GDPs). The introduction of an FTA between two large partners (1A, 1B) creates trade in more varieties than an FTA between two small partners (3A, 3B), and diverts trade from nonmembers in fewer varieties than two small partners, improving utility more in large countries relative to small countries. Moreover, the consequent larger net trade creation among two large economies causes a larger net expansion of demand and a consequent larger rise in real income. Small countries 3A and 3B face considerable trade diversion; the excess relative supply of factors in the small countries causes an erosion of relative real income. ${ }^{20}$ Consequently, the largest continent (1) should gain the most from a regional FTA.

Figures $4 \mathrm{a}$ and $4 \mathrm{~b}$ illustrate that welfare gains from natural FTAs on all three continents are monotonically higher the larger the endowments and real GDPs of the countries. In Figure $4 \mathrm{a}$, the plane for continent 1 is unambiguously above that for continent 2 , and the plane for continent 2 is unambiguously above that for continent 3 . Figure $4 \mathrm{~b}$ shows that - for any given values of $b$-the welfare benefits of regional FTAs increase monotonically with a larger market size. Figure $4 \mathrm{~b}$ assumes $a=0$; however, the monotonic relationship is robust to higher values of $a$ (figures not shown). 
Analogous reasoning applies to an unnatural FTA, the second exercise. If the two unnatural partners have a higher average absolute factor endowment, they will enjoy relatively higher net gains from an FTA. The second exercise reorients absolute factor endowments so that countries $1 \mathrm{~A}$ and $2 \mathrm{~A}$ (on different continents) have the largest endowments, countries $1 \mathrm{~B}$ and $3 \mathrm{~A}$ have the medium endowments, and countries $2 \mathrm{~B}$ and 3B have the smallest endowments. In Figure 4c, the top (bottom) plane represents the welfare benefits to an unnatural FTA for the two largest (smallest) countries. Figure 4d confirms the monotonic relationship_for given values of $a$ and $b$ - between economic size and the welfare benefits of an unnatural FTA.

Returning to the first exercise, continents are asymmetric in economic size. However, the formation of an FTA is symmetric; each pair of countries on each continent is assumed to form an FTA, as in Krugman and FSW. However, in the empirical work that will follow, we are more interested in the likely effect of an increase in the economic size of a pair of countries on the formation of an FTA between that pair of countries (i.e., probit analysis). We find that the effect on net welfare of a single natural or unnatural FTA still increases monotonically with the countries' absolute factor endowment sizes; see Figures 5a and 5b, respectively. Note that the welfare effects are qualitatively similar but quantitatively larger; with only one pair of countries forming an FTA, there is less trade diversion. $^{21}$

In the context of this class of models, it follows that the more similar two countries' market sizes are, the larger the gains from an FTA. In the context of the first exercise, suppose $1 \mathrm{~A}$ and $1 \mathrm{~B}$ have identical shares of the two countries' factor endowments. The formation of a natural FTA provides gains from net trade creation. By contrast, if $1 \mathrm{~A}$ has virtually all of the capital and labor on continent 1 , formation of an 
FTA would provide little trade creation since there is virtually no trade between 1A and 1B. Similar reasoning applies to unnatural FTAs in the second exercise.

Figures $6 \mathrm{a}$ and $6 \mathrm{~b}$ illustrate the negative monotonic relationship between disparity in country sizes and the welfare benefits from a natural and unnatural FTA, respectively, for any given values of $a$ and $b$ (here, assuming $a=0$ ). In Figure 6a, for instance, both countries gain from a natural FTA. For a given total economic size, as factor endowments are redistributed from one country (small) to the other country (large), the net welfare gain from an FTA erodes for the larger country. As disparity increases, the trade diversion vis-à-vis the ROW for the larger country rises relative to its diminishing trade creation with smaller FTA partners. As discussed in section II.E., a pair of countries' governments tends to enter an FTA as net welfare gains increase for each country. Since one of the country's net welfare declines with size disparity, the likelihood of an FTA decreases with disparity. These theoretical results suggest a third hypothesis:

Hypothesis 3: The net welfare gain from an FTA between a pair of countries increases the larger and more similar are their economic sizes (i.e., real GDPs).

Finally, we note that the previous hypothesis addresses the trade creation associated with economic characteristics of those two countries only. As in sections A and $\mathrm{B}$ above, surely the economic size of the ROW also matters. We can demonstrate that the trade diversion from an FTA between a country pair decreases, the smaller the absolute factor endowment size of the ROW, leading to:

Hypothesis 4: The net welfare gain from an FTA between a pair of countries decreases the larger is the economic size of the countries outside the FTA (i.e., ROW real GDP). 


\section{Asymmetric Industries}

At this point, asymmetries have been introduced between economies, but not between industries; a limitation of the Krugman-FSW model is the assumption of only one factor and one industry. For instance, Deardorff and Stern (1994) criticized the Krugman model as relying too heavily on the assumption of imperfect substitution (and hence, complete product differentiation). This parallel to the "Armington assumption" ensures that some of every country's products are consumed. This suggests that, with prohibitively high tariffs on nonbloc trading partners, regional FTAs would be "welfare disasters." Deardorff and Stern introduce instead a model with traditional comparative advantages of the Heckscher-Ohlin type. They conclude that the creation of a regional FTA improves welfare unambiguously. However, as Spilimbergo and Stein (1998) and Haveman (1998) note, the Deardorff-Stern model imposes unrealistic prohibitive tariffs on nonbloc trading partners that preclude trade diversion.

The only attempt that we are aware of to synthesize the complementary approaches of traditional Hecksher-Ohlin comparative advantage under perfect competition with the Krugman-FSW approach, featuring imperfect competition to analyze the welfare benefits of regional FTAs in the presence of transport costs, has been the work of Spilimbergo and Stein (1998). ${ }^{22}$ The limitation of Spilimbergo and Stein's two-factor, two-industry extension is that each industry uses only one factor of production (capital in manufactures, labor in agriculture); in their framework, countries' factor endowments "differ only in their capital endowment" (128). Consequently, differing capital-labor ratios only create differences in per capita income through scaleeconomies effects, and not through traditional comparative advantages. Changes in relative factor endowments cannot influence production shares and relative employment 
of capital and labor in sectors, since they assume capital and labor are immobile between sectors (an uncommon assumption to capture traditional Heckscher-Ohlin effects). As Haveman (1998) noted in his comment on Spilimbergo and Stein (1998):

On its face, their contribution appears to be more substantial than that of any other author. Other aspects of their model include countries of different sizes and varied degrees of bloc preference... On the other hand, it is not clear that production is present in other than its name. That is, in the absence of the ability to substitute capital for labor and vice versa, and a differentiated products model with the number of varieties given exogenously, is production really incorporated into the model in any meaningful way? I would contend that in fact it is not; what we have is really a world full of endowment economies (147).

By contrast, our model allows endogenous adjustment of capital and labor between sectors (that is, perfect factor mobility between sectors but not between countries) and endogenous determination of numbers of varieties. Consequently, our model can potentially separate differences between countries in per capita incomes due to scaleeconomies effects as well as specialization due to traditional comparative advantages; we also allow for potential differences in per capita incomes due to productivity differentials.

Until this point, both sectors have been symmetric in our analysis. We now introduce different parameters in the two industries' production functions. We assume "goods" are capital-intensive and "services" are labor-intensive in production, as in the Balassa-Samuelson model, cf., Kravis and Lipsey (1987, 1988) and Bergstrand (1991, 1992). Following Roland-Holst, Reinhart, and Sheills (1994), we set $\alpha_{\mathrm{g}}=0.36$ and $\alpha_{\mathrm{s}}=$ 0.27 (the capital shares in production). All other consumption and production parameters for the two sectors are assumed identical. Starting with all countries' initially having identical capital and labor endowments, we increase the capital stock of country $1 \mathrm{~A}$ to initiate a difference between the capital-labor endowment ratios of $1 \mathrm{~A}$ and $1 \mathrm{~B}$, but reduce 
proportionately the productivity of $1 \mathrm{~A}$ in both sectors $\left(z^{g}, z^{s}\right)$ to hold 1A's real GDP constant (to suppress scale-economies effects).

In traditional trade models (ignoring transport costs), the benefits of an FTA between a pair of countries should be enhanced, the wider their relative factor endowments, because traditional comparative advantages would be exploited more fully. Figure $7 \mathrm{a}$ illustrates the relationship between differences in capital-labor endowment ratios and the net welfare benefits from a natural FTA for the capital-abundant country (1A). At high intercontinental transport costs, the relationship is positive and monotonic. At high values of $b$, there is little intercontinental trade. Consequently, most variety is exchanged intracontinentally. As relative factor endowments widen, both countries specialize more in the industry where they have comparative advantages and enjoy more net welfare gains from an FTA. There is little loss of variety (trade diversion) for 1A, as relatively capital-abundant $1 \mathrm{~A}$ produces more goods and less services, but relatively labor-abundant 1B produces more services and less goods.

However, at low intercontinental transport costs, the net gains from an FTA increase at first with wider relative factor endowments, but eventually decline. At low values of $b$, there is considerable intercontinental trade in goods and services. As relative factor endowments widen, country 1A gains initially from specialization in goods. Yet, at high levels of specialization, 1A relies more on intra- and intercontinental trade to meet its demand for varieties of services. Hence, at low values of $b$, a natural FTA causes considerable trade diversion of services intercontinentally. Thus, with increasing specialization, the net welfare gains from interindustry trade are eventually offset by the net trade diversion due to intraindustry trade. ${ }^{23}$ A qualitatively similar relationship holds for an unnatural FTA (see Figure 7b). Consequently, the relationship between the net 
benefits from an FTA and wider relative factor endowments is likely positive, but possibly quadratic (if intercontinental transport costs are very low, leading to:

Hypothesis 5: The net welfare gain from an FTA between a pair of countries increases at first, with wider relative factor endowments, but eventually declines due to increased specialization (if intercontinental transport costs are low).

As in the previous section, this hypothesis concerns only trade creation between the country pair and the pair's capital-labor ratios. Trade diversion for the country pair will be greater the more Heckscher-Ohlin trade is foregone (up to a point). We can demonstrate readily (figures not shown) that the trade diversion from an FTA between a country pair is less the smaller the difference between the relative factor endowment size of the country pair and that of the ROW, leading to:

Hypothesis 6: The net welfare gain from an FTA between a pair of countries decreases the larger the difference is between the relative factor endowment of the country pair and that of the ROW.

We will now evaluate the six hypotheses empirically.

\section{Econometric Issues and Data}

The goal of this study is to provide the first empirical estimates of the economic determinants of FTAs. As Lawrence's quote in the introduction suggests, FTAs may well be an endogenous variable, likely adopted by a pair of countries' governments when the welfare "benefits outweigh the costs" (59).

\section{A. Econometric Issues}

The econometric framework we employ is the qualitative choice model of McFadden (1974, 1975, 1976). The qualitative choice model is appropriate to evaluating the economic determinants of governments forming an FTA because, as noted earlier, 
"Governments ...are often given the general mandate to maximize 'public welfare"'(McFadden 1975, 401).

A qualitative choice model can be derived from an underlying latent variable model. For instance, let $y^{*}$ denote an unobserved, or latent, variable, where, for simplicity, we ignore the observation subscript. As in Wooldridge (2000a), let $y^{*}$ in the present context represent the difference in utility levels from an action (the formation of an FTA), where:

$$
y^{*}=\beta_{0}+x \beta+e
$$

where $\boldsymbol{x}$ is a vector of explanatory variables (i.e., economic characteristics), $\beta$ is a vector of parameters, and error term $e$ is assumed to be independent of $\boldsymbol{x}$ and to have a standard normal distribution. ${ }^{24}$ In the context of our model formally $y^{*}=\min \left(\Delta U_{\mathrm{i}}, \Delta U_{\mathrm{j}}\right)$. Hence, both countries' consumers need to benefit from an FTA for their representative countries to form one.

Since $y^{*}$ is unobservable, we define an indicator variable, FTA, which takes the value 1 if two countries have a free trade agreement (indicating $y^{*}>0$ ), and 0 otherwise (indicating $y^{*} \leq 0$ ). We can derive the response probability, $\mathrm{P}$, for FTA as:

$$
\mathrm{P}(F T A=1)=\mathrm{P}\left(y^{*}>0\right)=\mathrm{G}\left(\beta_{0}+x \beta\right)
$$

where $\mathrm{G}(\mathrm{)})$ is the standard normal cumulative distribution function, which ensures that $\mathrm{P}(F T A=1)$ lies between zero and unity. The standard errors of the coefficient estimates of $\beta$ are asymptotically normally distributed. Thus, standard z-statistics are reported in Table 1 in section $\mathrm{V}$ (part $\mathrm{A}$ ) and indicate whether the coefficient estimates of $\beta$ are 
statistically significant (see Wooldridge 2000a). An analysis of the robustness of these estimates follows in section V (part B).

While the statistical significance of the probit estimates can be determined, the coefficient estimates themselves can only reveal the signs of the partial effects of changes in $\boldsymbol{x}$ on the probability of an FTA, due to the nonlinear nature of $\mathrm{G}($ ). Let $\mathrm{E}($ ) denote the expectation of a variable. For the probit function, the direction of the effect of variable $x_{j}$ on $\mathrm{E}\left(y^{*} \mid \boldsymbol{x}\right)=\beta_{0}+\boldsymbol{x} \beta$ is only qualitatively (not quantitatively) identical to the effect of $x_{j}$ on $\mathrm{E}(F T A \mid \boldsymbol{x})=\mathrm{G}\left(\beta_{0}+\boldsymbol{x} \beta\right)$. To estimate the partial effects of changes in $x_{j}$ on $\mathrm{P}(F T A=1)$, we will need to estimate directly the partial effects on the response probabilities in section V (part C). Since the response probabilities account for nonlinearity, the estimated effects of each variable on the probability of an FTA are sensitive to the levels of variables, consistent with our theory. In section VI, we examine individual predicted probabilities and outcomes, and compare the predicted FTAs to actual FTAs.

\section{B. Data Issues}

We now describe the data used. The first challenge was to create an index of FTAs. Going back to Linnemann (1966) and Aitken (1973), a plethora of international trade studies have measured the presence or absence of an FTA between a pair of countries using a binary variable; see Frankel (1997, Ch. 4) for a thorough survey. Following those studies, the variable $F T A_{i j}$ will have the value 1 for a pair of countries $(i, j)$ with a free trade agreement in 1996 , and 0 otherwise. This variable was constructed for the pairings of 54 countries [hence, $(54 \times 53) / 2$ or 1,431 pairings] using appendices in Lawrence (1996) and Frankel (1997), and FTAs notified to the GATT/WTO under GATT Article XXIV or the Enabling Clause for developing economies as of November 1999 (WTO 1999); we included only full (no partial) FTAs and customs unions. 
In undertaking an empirical analysis of economic determinants of FTA, one has to be sensitive, of course, to the guidance provided by the underlying theoretical model. The Krugman and FSW models introduced an abstraction that made transparent the guiding economic geography factors in explaining the benefits of a regional FTA in their models, namely, that some country pairs face only intracontinental transport costs $(a)$ and other country pairs face intra- and intercontinental transport costs $(a, b)$. The dichotomy between inter- and intracontinental transport costs was simply an abstraction to emphasize that two countries that are closer geographically will tend to have lower transport costs. The lower transport costs are between two countries (ignoring their distance from the ROW), the more each country can consume the other country's varieties, enhancing trade creation regionally (Hypothesis 1). As the primary factor influencing such costs is bilateral distance, this task amounted to calculating 1,431 bilateral distances among 54 countries' economic centers. Distances were calculated in nautical miles using US Department of the Navy (1965) for sea distances and Rand McNally (1988) for land distances (the latter multiplied by a standard factor of 2 for the transport-cost differential between land and sea transport). We used Linnemann (1966) for economic centers of countries, as in Bergstrand $(1985,1989)$. The variable $N A T U R A L_{i j}$ (denoting natural trading partners) is the natural logarithm of the inverse of the distance between the economic centers of $i$ and $j$.

While measuring closeness is relatively straightforward, measuring the "remoteness" of a pair of continental trading partners from the ROW is less straightforward. To analyze Hypothesis 2, we constructed REMOTE: 
$\operatorname{REMOTE}_{\mathrm{ij}}=\operatorname{DCONT}_{\mathrm{ij}} \mathrm{x}\left\{\left[\log \left(\sum_{\mathrm{k}=1, \mathrm{k} \neq i, \mathrm{j}}^{\mathrm{N}}\right.\right.\right.$ Distance $\left._{\mathrm{ik}} / \mathrm{N}-1\right)+\log \sum_{\mathrm{k}=1, \mathrm{k} \neq \mathrm{i}, \mathrm{j}}^{\mathrm{N}}$ Distance $\left.\left.\left._{\mathrm{jk}} / \mathrm{N}-1\right)\right] / 2\right\}(15)$

The interpretation of REMOTE is as follows. First, DCONT is a binary variable assuming the value 1 if both countries are on the same continent, and 0 otherwise. If two countries $(i, j)$ are on the same continent, REMOTE measures the simple average of (the natural logarithms of) the mean distance of country $i$ from all of its trading partners except $j$ and the mean distance of country $j$ from all of its trading partners except $i$. If two countries $(i$, $j$ ) are on different continents, then REMOTE has the value 0 . This measure captures the spirit of $b$ for natural FTAs because it measures how far two countries on the same continent are from other countries, but it has no value for unnatural trading partners. As discussed in section III, for any given value of intracontinental transport costs $(a)$, only the welfare gains from a continental FTA increase monotonically with increases in intercontinental transport costs $(b)$.

Other economic variables were readily measurable. Data on populations, real GDPs, per capita real GDPs, and per worker physical capital stocks (all in international dollars) are from Baier, Dwyer, and Tamura (2000), assembled from primary data in Mitchell (1992, 1993, 1995); availability of capital stock data determined the sample of countries. ${ }^{25}$ Despite the cross-sectional nature of the decision, an issue of potential endogeneity arises. In the context of our theoretical model, the decision of two countries to have an FTA or not in 1996 depends upon economic characteristics in 1996. While measures of closeness and remoteness are time-invariant, measures such as income, per capita income, and factor endowments vary over time and have likely been influenced by trade liberalization. ${ }^{26}$ For many country pairs in our sample, an FTA between two countries in 1996 was formed well before 1996, the earliest (the original six-member, European Economic Community (EEC) was phased in over 10 years beginning in 1958; the next was European Free Trade Association (EFTA) beginning in 1961. Since an FTA 34 
formed several years prior to 1996 likely influenced subsequent trade-which consequently influenced economic growth-incomes and capital stocks in 1996 (variables in $\boldsymbol{x}$ ) may well be endogenous to the dependent variable, FTA. To account for this, we used the earliest data on incomes, capital stocks, and populations available in Baier, Dwyer, and Tamura (2000) for a wide sample, namely, 1960 data. $^{27}$

\section{Empirical Results}

The empirical results are presented in three sections. In section A, we evaluate the results from the probit models to focus on whether the economic attributes of pairs of countries have the expected qualitative relationships with the likelihood of an FTA and to determine the statistical significance of the probit estimates. In section $\mathrm{B}$, we evaluate the robustness of the probit estimates. In section $\mathrm{C}$, we calculate the partial effects on the response probabilities to determine if standard deviation changes in the economic variables have economically significant effects on the probability of an FTA.

\section{A. Probit Results}

Table 1 presents the coefficient estimates and associated z-statistics from the probit regressions. To aid the reader, we present results for six probit regressions associated with five of the six hypotheses generated in the theoretical results. In the context of the qualitative choice framework and the theoretical model, two countries will have a higher probability of forming an FTA if the welfare benefits outweigh the welfare costs. The first testable hypothesis from the theory is that the probability of an FTA is higher as the distance between the countries' economic centers falls. Specification (column) 1 shows that the first hypothesis is supported; the likelihood of an FTA is greater the more natural two countries are as trading partners. ${ }^{28}$ 
The second testable hypothesis is that—for a given distance of two countries from one another-two continental trading partners will have a higher probability of forming an FTA the more remote they are from the ROW. REMOTE $E_{i j}$ measures the remoteness of a pair of continental partners. Column 2 demonstrates that REMOTE is positively related to the probability of an FTA as expected and the coefficient estimate is statistically significant at the 1 percent significance level.

The third testable hypothesis is that the probability of an FTA is higher the larger and more similar economically are the trading partners, after accounting for distance and remoteness. $R G D P_{i j}$ measures the sum of the logs of real GDPs of countries $i$ and $j$ in 1960. $D R G D P_{\mathrm{ij}}$ measures the absolute value of the difference between the logs of real GDPs of countries $i$ and $j$ in 1960. Column 3 reveals that pairs of countries with larger average real GDPs and smaller differences in real GDPs have a higher probability of an FTA, in accordance with Hypothesis 3.

The fourth hypothesis is that the probability of an FTA is lower, the larger the ROWs economic size, due to potential trade diversion. Unfortunately, capturing this effect empirically is problematic. In a cross-section of country pairs, the ROW's GDP does not vary much across the 1,431 observations. The variable-ROWRGDP $P_{i j}$ is calculated as the average of the logs of two countries' ROW real GDPs, where each country's ROW real GDP is the sum of the other 53 countries' real GDPs (divided by 53). Not surprisingly, the variance in this variable is trivial (since each observation roughly equals world real GDP, a constant across country pairs), and consequently this variable is useless to explain FTAs. The minimum (maximum) value of this variable is 18.1 (18.3), and the variable's standard deviation is 0.04 . Hence, the coefficient of variation was 0.002 , compared with the next smallest coefficient of variation in our data set of 0.06. Consequently, we excluded this variable. 
The fifth testable hypothesis is that the probability of an FTA is higher, the larger the difference between two countries' relative factor endowments, but possibly only up to a point. If intercontinental transport costs are not very low or relative factor endowment differences are not very high, then the quadratic term may not be important. $D K L_{i j}$ measures the absolute value of the difference between the logs of the capital-labor ratios of countries $i$ and $j$ in 1960; $S Q D K L_{i j}$ measures the square of $D K L$. $D K L$ should be positively related to $P(F T A=1)$ while $S Q D K L$ should be negatively related to it. Column 4 reveals that $D K L$ has the expected positive effect. Larger relative factor endowment differences between the country pair, likely capturing gains from Heckscher-Ohlin trade creation between the pair, have a positive and statistically significant relationship with the probability of an FTA.

Column 5 reveals that the variables have the expected quadratic relationship with $P(F T A=1)$, but the coefficient estimate of $D K L$ loses explanatory power and the coefficient estimate for the quadratic term, while having the expected negative sign is statistically insignificant. The overall explanatory power from adding the quadratic term is negligible; the pseudo- $\mathrm{R}^{2}$ of specification 5 is identical to that of specification 4 . Consequently, in subsequent regressions we omitted the quadratic term.

The sixth and final hypothesis is that the probability of an FTA declines the greater the difference between the capital-labor ratios of the member countries and the ROW's capital-labor ratio, due to potential trade diversion. This variable-DROWKL $L_{i j}$ - is measured as: 
$D R O W K L_{i j}=\left\{\mid \log \left[\left(\sum_{\mathrm{k}=1, k \neq \mathrm{i}}^{\mathrm{N}} \mathrm{K}_{\mathrm{k}}\right) / \sum_{k=1, \mathrm{k} \neq \mathrm{i}}^{N} L_{k}\right)\right]-\log \left[\mathrm{K}_{\mathrm{i}} / \mathrm{L}_{\mathrm{i}}\right] \mid+\log \left[\sum_{\mathrm{k}=1, \mathrm{k} \neq \mathrm{j}}^{\mathrm{N}} \mathrm{K}_{\mathrm{k}}\right) /$

$\left.\left.\left(\sum_{k=1, \mathrm{k} \neq \mathrm{j}}^{N} L_{k}\right]-\log \mathrm{K}_{\mathrm{j}} / L_{j}\right] \mid\right\} / 2(16)$

Consistent with Hypothesis 6, DROWKL has a negative relationship with the probability of an FTA and its coefficient estimate is statistically significant, likely due to the potential interindustry trade diversion.

On net, the probit model works well. All RHS variables in specification 6 have the expected sign and their coefficient estimates are statistically significant. Using the pseudo- $\mathrm{R}^{2}$ term as a summary measure of explanatory power, specification 6 "explains" 70 percent of the variation of FTAs among 1,431 country pairings in 1996. The pseudo$\mathrm{R}^{2}$ measure is the one used in McFadden (1974), one minus the ratio of the log-likelihood value for the estimated model to the log-likelihood value for the model with only an intercept.

An alternative measure of goodness of fit for probit models is the "percent correctly predicted," discussed in Wooldridge (2000a). In this measure, we compute the estimated probability of an FTA for each pair. If the estimated probability of the pair exceeds 0.5 , we define a variable PredFTA to be one; if the probability is less than 0.5 , PredFTA takes on the value zero. The percentage of times that PredFTA matches FTA (1 if an FTA exists, and 0 otherwise) is an alternative measure of goodness of fit. However, Wooldridge notes that it is even more useful to report the percent correctly predicted for each of the two possible outcomes, for the following reason. With 1,431 country pairs and 289 FTAs, a probit specification of FTA on a constant only would result in predicted values of FTA of 0.202 for every observation (i.e., 289/1,431). In this naive specification, however, PredFTA would still match FTA for 1,142 of the 1,431 cases, or 79.8 percent. Thus, even if the model failed to predict even one FTA correctly, this goodness-of-fit measure would suggest a predictive power of 80 percent. 
Consequently, we report the percent correctly predicted for each of the two possible outcomes. In our sample of 1,431 pairs, 289 pairs have an FTA and 1,142 pairs do not have an FTA. Using the rule described, 240 of the 289 FTAs are predicted correctly, or 83.04 percent. Also, 1,112 of the 1,142 pairs without an FTA are predicted correctly, or 97.37 percent. Thus, the model appears using alternative criteria to have a reasonably good fit.

\section{B. Robustness}

In this section, we evaluate the sensitivity of the results to several potential econometric issues. First, the specifications assume that the dependent variable $\left(F T A_{\mathrm{ij}}\right)$ is independent across observations. In reality, a free trade agreement between the United States and Mexico is not independent of such an agreement between the United States and Canada. That is, certain pairings of countries belong to a group or "cluster." The lack of independence of observations influences potentially the variance-covariance matrix of the econometric model. Akin to adjusting for heteroskedasticity, we re-estimated the specification in column 6 to adjust for the possible interdependence of bilateral observations. This correction has an effect only on the standard errors, not the coefficient estimates. We assumed that pairs of countries within certain clusters (e.g., members of the EU) were interdependent, but clusters were independent. Clusters had three major categories: both countries belonged to an FTA, one of the countries in the pair belonged to an FTA, or neither country belonged to an FTA. We defined 99 clusters. The interdependence of observations within clusters had no significant effect on the standard errors and thus was not a major concern. Hence, in the following empirical work, this issue was ignored. 
Second, as noted earlier, time-varying RHS economic variables were measured using 1960 data to ensure predetermined values in the estimation; 1996 values of incomes and capital stocks would have been potentially endogenous. We implemented the test for endogeneity of the 1996 values of income and capital stocks proposed by Rivers and Vuong (1988). The test for endogeneity is a Wald test. The test statistic is a $\chi^{2}$ statistic with four restrictions; the critical value is 13.28 at the 1 percent level. The $\chi^{2}$ statistic was 61.41. The null hypothesis of exogeneity of 1996 values of incomes and capital stocks was rejected. This is consistent with our theory that trade policy, by influencing the terms of trade and other factors, influences income and capital investment and is consistent with recent empirical evidence in Frankel and Romer (1999).

Third, consistent with our assumption that FTAs are formed by governments maximizing consumer welfare, we have not introduced any "political" variables. In the context of our theory, such variables' inclusion would be ad hoc. However, readers may be concerned that-despite the theory-the results may be biased by omitting some important political, social, and cultural factors that may be relevant. Attempting an exhaustive examination of all such potential noneconomic variables is clearly outside the scope of this paper. We examined three of these variables: an index of the countries average degrees of "market orientation," a dummy variable to reflect shared legal origins (i.e., British law, etc.), and a dummy variable for having a common language. None of these variables was statistically significant and therefore we have ignored them. ${ }^{29}$

Finally, it could be argued that the importance of bilateral distance and remoteness in explaining the likelihood of an FTA may well be driven by the presence of the EU and the size of the EU (in real GDP and number of countries). Moreover, it could also be argued that countries that have obtained an FTA with the EU (e.g., Turkey) are driven by the attractive market size of the entire EU, rather than by the economic size of 
individual EU member countries (e.g., Denmark). To address this issue, we re-estimated specification 6 for three subsamples of our entire 1,431 observations. The results are presented in Table 2. For comparison, the first column reports again the results of specification 6 for the full sample. Column 2 reports the results for a subsample excluding any country pair that included an EU member. The results are qualitatively identical to those in Table 1, and all the coefficient estimates remain statistically significant at the 1 percent level (except for $D K L$ ). Similar results are obtained when the sample excludes any country pair that includes a Western European country or a European country (columns 3 and 4, respectively). Thus, the results for specification 6 are basically robust to the exclusion of all of Europe, the most geographically clustered group of countries.

\section{Partial Effects of RHS Variables on Response Probabilities}

As discussed earlier, the probit estimates cannot reveal the quantitative effect of a change in any RHS variable on the probability of an FTA. Given the standard normal cumulative distribution function $\mathrm{G}($ ), the partial effect on the response probability of FTA (denoted $p_{x j}$ ) to a one standard deviation change in any variable $x_{j}$, $\hat{\mathrm{o}}_{x j}$, is:

$$
P_{x j}=\mathrm{G}\left[\hat{\beta}_{\mathrm{o}}+\sum_{\mathrm{i} \neq \mathrm{j}} \hat{\beta}_{i} \bar{\chi}_{\mathrm{i}}+\hat{\beta}_{\mathrm{j}}\left(\bar{\chi}_{j} \pm \hat{\sigma}_{x j}\right)\right]-\mathrm{G}\left[\hat{\beta}_{\mathrm{o}}+\sum_{\mathrm{i} \neq \mathrm{j}} \hat{\beta}_{i} \bar{\chi}_{i}+\hat{\beta}_{\mathrm{j}} \bar{\chi}_{j}\right]
$$

where $\bar{x}_{i}$ denotes the mean level of $x_{i}$.

Note that $p_{x j}$ is sensitive to the levels of the elements of $\boldsymbol{x}$. This accords with our theoretical model. This issue is illustrated most transparently by reconsidering Figure 1 in section III. The net welfare gain from an FTA between natural, rather than unnatural, trading partners is sensitive to the level of intercontinental transport costs $(b)$, reflecting how remote continents are. Analogous nonlinearities arise in our generalization of the 
FSW model. For instance, consider how the effect of an increase in economic size on the net welfare gain from an FTA is sensitive to whether the countries are natural or unnatural trading partners. Figures $5 \mathrm{a}$ and $5 \mathrm{~b}$ in section III illustrate this. In Figures 5a and $5 \mathrm{~b}$, at $b=0.1$ (and $a$ is assumed equal to 0 ), the net welfare gain from a natural or unnatural FTA is positive. Suppose absolute factor endowments double for each country pair (from 100 to 200). The percentage net welfare gain from a FTA from doubling the factor endowment rises from 2.492 percent to 2.909 percent, or by 0.417 percent, for the natural pair. By contrast, the percentage net welfare gain from a FTA from doubling the factor endowment rises from 1.773 percent to 2.145 percent, or by 0.372 percent, for the unnatural pair. Thus, we expect a one standard deviation increase in economic size to have a larger effect on the probability of an FTA for natural trading partners than unnatural ones. Similarly, the effects of an increase in disparity in economic sizes, differences in capital-labor ratios, bilateral distance, and remoteness are sensitive to the levels of the other variables. Following convention, the mean values of the RHS variables are used for the levels.

One complication arises in estimating the partial effects on the response probabilities for the particular vector of RHS variables, $\boldsymbol{x}$, in our model by using (by convention) the mean values for the levels. One of the RHS variables, REMOTE, is the product of a continuous variable and a binary variable. Thus, the variable has the value of two countries' distance from the ROW when the pair share a continent, but 0 if not on the same continent. Thus, the mean value of this particular variable is economically meaningless. To account for this, we estimate the partial effects on the response probabilities for two scenarios, one with the mean value of NATURAL and the mean value of REMOTE when the two countries are continental partners, and one with the 
mean value of NATURAL and 0 as the value of REMOTE when the two countries are unnatural partners.

Tables $3 \mathrm{a}$ and $3 \mathrm{~b}$ present the response probabilities under these two alternative scenarios for a one standard deviation change in each of the RHS variables along with (in parentheses) the 95 percent confidence interval associated with the respective response probability. Table 3 a presents the response probabilities for natural trading partners. For ease of information, we note that at the mean level of all RHS variables the probability of an FTA among natural partners is $0.850 .{ }^{30} \mathrm{~A}$ standard deviation increase (decrease) in the closeness of such partners increases (decreases) this probability by $0.140(0.447)$. The differential partial effect is due, of course, to the nonlinear functional relationships. Not surprisingly, a standard deviation change in distance has an economically and statistically significant effect on the probability of an FTA among natural partners. A standard deviation increase (decrease) in the remoteness of two natural trading partners from the ROW increases (decreases) the probability of an FTA by 0.008 (0.008).

Geographic proximity is not the only factor influencing the probability of an FTA. For instance, changes in the level of or disparity between countries' real GDPs have economically and statistically significant impacts on $\mathrm{P}(F T A=1)$. For instance, a standard deviation increase in the level of real GDPs increases the response probability by 7.5 percentage points, more than half the effect of a standard deviation increase in closeness. Standard deviation changes in the difference between real GDPs and between capitallabor ratios all have economically and statistically significant impacts of approximately the same magnitudes as real GDP levels.

Table $3 \mathrm{~b}$ reports the response probabilities for unnatural country pairs. Not surprisingly, at the mean level of all RHS variables the probability of an unnatural FTA is 
less than 1 percent. ${ }^{31}$ A standard deviation increase in closeness causes this probability to rise from 0.004 to 0.093 , reinforcing the importance of economic geography in the likelihood of an FTA; this effect is statistically significant. Economic factors still manage a role in influencing the likelihood of an unnatural FTA. For instance, a standard deviation rise in the level of real GDPs increases the response probability of an FTA by 1 percentage point; this effect is economically and statistically significant. A standard deviation decrease in the absolute difference between real GDPs of unnatural partners has a similar economically and statistically significant positive effect on the probability of an FTA (1 percentage point). Increases in the differences between capital-labor ratios also have economically and statistically significant effects on $\mathrm{P}(F T A=1)$.

Thus, the response probability estimates confirm that economic characteristics as well as geography have economically and statistically significant impacts on the probability of an FTA. While the size of these partial effects varies between natural and unnatural partners as theory suggests, the results support the theory that economic characteristics associated with intraindustry trade in differentiated products, interindustry trade reflecting differences in relative factor endowments, and inter- and intracontinental transport costs all help to explain the likelihood of FTAs.

\section{Interpreting the Results}

If governments maximized the welfare of their citizens, prospective moves toward regional free trade would almost surely do more good than harm to the members of the free trade areas (Krugman 1991b, 21).

The original "Krugman vs. Krugman" debate yielded unambiguous conclusions. In a world with symmetric economies and no transport costs, bilateralism was bad; in the same world with prohibitive intercontinental transport costs, bilateralism was good. FSW illustrated that the answer to the question was ambiguous, depending upon the degree of 
intercontinental transport costs. Drawing upon empirical data for intercontinental transport costs external to the model, they concluded that regionalization may have become excessive.

In a world with asymmetric economies, we cannot make any such sweeping statements that bilateralism is "good" or "bad." The focus of this paper has been on explaining and predicting FTAs bilaterally based upon pure economic characteristics (of member and nonmember countries). However, as Krugman's quote above suggests, we can make limited statements about net welfare gains or losses for the member countries.

In the context of McFadden's motivation of qualitative choice models, the predicted probabilities of an FTA suggest whether particular pairs of countries should have an FTA based upon economic characteristics that-in the context of the theory-enhance welfare. If the predicted probability of an FTA for a country pair exceeds one-half, this suggests - in this framework - that there is a net welfare gain for the country pair. As the empirical results show, the probability of an FTA exceeded onehalf for 240 of the 289 country pairs with FTAs, or 83.04 percent. The results suggest—in the model's context—that bilateralism is good for these country pairs (though not necessarily for nonmembers).

Second, although 240 of the FTAs in existence were predicted, 49 of the remaining 289 country pairs with FTAs were not predicted. In the context of the model, this suggests that 17 percent of the FTAs in our sample were welfare-reducing for the two countries. One might say that, for these country pairs, bilateralism was "excessive."

Third, our qualitative choice model also allows us to identify for which country pairs bilateralism might be considered "insufficient." Bilateralism is termed "insufficient" if an FTA is predicted but does not exist (yet). Of the 1,142 country pairs without an 
FTA, 1,112 pairs were predicted correctly, or 97.37 percent. We note that 30 country pairs that had no FTA should have such an agreement (according to the model's predictions); these are shown in Table 4 along with each pair's predicted probability in parenthesis. ${ }^{32}$ Table 5 shows the 49 cases where bilateralism was "excessive," that is, where an FTA existed in 1996 but the model's prediction probability was less than onehalf. Six cases involve agreements between Algeria and EC members, and 10 cases involve agreements between Egypt and EC members; these agreements went into force in 1976 and 1977, respectively, although evidence suggests that Algeria's and Egypt's imports from the EC still face high tariffs. Eight cases involve Turkey and EC members; the EC-Turkey agreement was notified to the GATT/WTO in 1995, legally entered into force January 1996, and is still under examination. Evidence suggests that this agreement is effective. ${ }^{33}$ Three more cases include remnants of the former British Empire: UKCanada, UK-Australia, and Canada-Australia FTAs. According to the model, the probabilities that these three countries would form FTAs in 1996 are 28.3, 0.3, and 0.1 percent, respectively.

Thus, although 17 percent of the FTAs in existence were not predicted, it is important to note that 27 of the 49 cases of "excessive" bilateralism are exhibited by FTAs formed: (1) between the EC and Algeria, Egypt, and Turkey and (2) between former British Commonwealth members (UK, Canada, and Australia). Hence, over half of the cases of excessive bilateralism are limited to just a few countries.

We conclude this section by addressing two points. First, we are well aware that, in the real world, the formation of an FTA between countries is likely influenced by both economic and political factors. While we have omitted political factors influencing the formation of an FTA intentionally, we recognize the importance of these factors, as emphasized in papers on the political economy of trade policy. The purpose of this paper 
has been to attempt to provide a "benchmark" of the pure economic determinants of FTAs to provide foundations for a future formal synthesis of political and economic variables.

However, this is an appropriate place to discuss potential departures from our competitive setting. As discussed in the large literature on endogenous trade policy, social welfare and political special interests may likely influence the formation of an FTA. As Trefler (1993) notes, common across many cross-industry endogenous tariff protection studies is the empirical result that protection tends to be higher in industries with greater import penetration. As mentioned in footnote 29 , when the bilateral trade between the country pairs was the sole RHS variable, the coefficient estimate was positive and significant; however, the pseudo- $\mathrm{R}^{2}$ was considerably smaller than any of the specifications in Table 1. However, the additional inclusion of the level of trade between a country pair into specification 6-already holding constant the pair's economic size and other economic determinants—can be a crude proxy for import "penetration"; the expected coefficient estimate should be negative. In this enhanced specification, the countries' bilateral trade in 1960 had a negative relationship with the probability of an FTA, consistent with the endogenous protection literature. However, the coefficient estimate's magnitude was small $(-0.13)$ and the estimate was statistically insignificant at the 1 percent significance level (though significant at 5 percent; $z=-2.11$ ). The other coefficients' estimates did not change materially. This is consistent with the FTA decision's predominantly reflecting consumer welfare.

Recently, Grossman and Helpman (1995) have addressed the "politics" of free trade agreements. The conclusion of their political economy analysis suggests that the formation of an FTA by two countries' governments is more likely when there are 
substantial economic welfare gains for each country's average voter, similar to our model. In their model, with specific factors owned by a few concentrated firms, they find that political pressure to prevent an FTA is reduced the more "balanced" is potential trade between the partner countries, due to offsetting political pressures from exporters and importers. To try to capture the spirit of Grossman and Helpman's analysis, we also reestimated specification 6 including the absolute value of the difference between the logarithms of the two countries' trade flows in 1960 (as well as the average trade level). The result was that differences in trade volumes (representing "imbalance" between potential trade of the partners) had a negative relationship with the probability of an FTA. However, with both trade variables included, neither was significant at the 5 percent level (though both were significant at the 10 percent level). The inclusion of both variables had no perceptible impact on the coefficient estimates of the main specification 6 (or their statistical significance). More importantly, none of the estimated FTA predictions were altered materially (the model predicted 238, rather than 240, of the existing FTAs).

We note that Goldberg and Maggi (1999) found empirical evidence that consumers' economic welfare had an estimated weight of 98 percent relative to the political factors' weight of 2 percent in explaining US trade policy. Thus, we argue that the economic benchmark provided in this study offers not only a sound analytical and econometric initial step toward a more comprehensive understanding of the determinants of FTAs, but a benchmark upon which future research might incorporate, in a sound analytical manner, political factors as well.

The literature on free trade agreements has primarily been a theoretical one. Empirical evaluation of free trade agreements has largely fallen into two camps: computable general equilibrium (CGE) models of trade and trade policy and econometric analyses of trade flow impacts of FTAs. First, common to both approaches-and 
different from ours-is that FTAs are exogenous instruments. Second, CGE analyses generally focus on the trade creation and trade diversion impacts of an FTA, calculating the impacts in terms of a share of GDP. As is well known, however, CGE studies are essentially, as Baldwin and Venables (1995) note, "theory with numbers." Such analyses provide a quantitative articulation of what the underlying theoretical model suggests. However, with policies as exogenous instruments, these analyses do not explain the formation of FTAs.

Econometric analyses of the impacts of FTAs tend largely to explore the ex post effect of an FTA on trade flows, often using "gravity equations" such as in Aitken (1973) and Sapir (1981). While these models, when properly specified, have successfully indicated gross trade creation and diversion from an FTA, welfare statements cannot be deduced from them. As with CGE models, the gravity equations do not explain the (endogenous) formation of FTAs. Thus, we see the approach in this paper as a complement to these alternative approaches in providing quantitative insight about FTAs.

In conclusion, we note Leamer's quote, "Give me data or give me death.” Leamer (1998), in commenting upon Spilimbergo and Stein (1998), noted that answers to questions such as the one in this paper "should be sought using four different methodologies: theory, calibration, indirect estimation, and direct observation" (149). This paper has attempted to address the issue of bilateralism intentionally using all four methodologies. We have constructed a fairly parsimonious model of international trade with monopolistic competition as well as Heckscher-Ohlin trade in a setting with explicit transportation costs. Despite parsimony, the complexity of the model requires calibration to determine qualitative theoretical relationships. Turning to the qualitative choice econometric literature, we applied observations on FTAs and economic characteristics of 
countries to determine the predictability of FTAs for particular pairs and to draw inferences about the net welfare gain or loss for these pairs. We found that country pairs that have bilateral FTAs tend to have those selected economic characteristics that should enhance economic welfare for the pair. Using direct observations, we found evidence that individual cases of "excessive" bilateralism are constrained to a few plausible pairs of countries.

\section{Conclusions}

The main purpose of this study was to develop an econometric model that explains the "pure economic" determinants of FTAs and that also predicts successfully the likelihood of pairs of countries forming FTAs. The econometric model is formulated based upon an explicit general equilibrium theoretical model of world trade of multiple countries on multiple continents in the presence of two monopolistically competitive product markets and two factors of production with explicit inter- and intracontinental transport costs. This is the first econometric model, to our knowledge, that predicts FTAs based upon an explicit general equilibrium model. Moreover, it provides a economic benchmark for future political economy frameworks to enhance the explanation of FTA determinants.

The main conclusions of the study are that the potential welfare gains and likelihood of a free trade agreement (FTA) between a pair of countries are higher:

(i) the closer the two countries are as trading partners, because of greater trade creation;

(ii) the more remote a natural pair is from the rest of the world, because of less trade diversion;

(iii) the larger and more similar economically (i.e., real GDPs) two trading partners are, by exploiting economies of scale in the presence of differentiated products and more trade creation; 
(iv) the greater the difference in capital-labor endowment ratios between two countries, due to the gains from traditional comparative advantages (i.e., Heckscher-Ohlin trade) and more trade creation; and

(v) the less is the difference in capital-labor endowment ratios of the member countries relative to that of the ROW, due to less interindustry trade diversion.

These factors have economically and statistically significant effects on the probability of an FTA using a probit model.

One measure of overall fit of a probit model is how well the model predicts correctly the outcome. Of the 1,431 country pairs in our sample, 289 country pairs had an FTA and 1,142 pairs did not have an FTA in 1996. Using economic data from 1960, 240 of the 289 FTAs were predicted correctly, or 83.04 percent. Also, 1,112 of the 1,142 pairs without an FTA were predicted correctly, or 97.37 percent.

Is bilateralism good? Unlike the restrictive symmetric models of Krugman and FSW, we cannot make any sweeping statement. While we predict well over half of the FTAs in our sample in 1996, we find that 49 of the 289 FTAs in 1996 were not predicted, suggesting that 17 percent of the FTAs in that year are "excessive" in a strict interpretation of the results. Yet, two important caveats are worth noting. First, of these 49 cases, 24 are agreements between the EC and Algeria, Egypt, and Turkey. Thus, half of the cases of excessive bilateralism are limited to three particular countries (and the Algeria and Egypt agreements may not even be effective). Second, we found 30 cases where agreements should exist (in the context of the model) but none did, suggesting for these pairs that bilateralism has been insufficient. 


\section{Endnotes}

1 A similar distinction is discussed in Kowalczyk and Davis (1998).

2 The static effects are the net gains to a country's representative household from an FTA due to changes in trade volumes, trade distortion costs, or terms of trade that would arise in a perfectly competitive framework (with constant returns). These potential gains would be supplemented in the monopolistically competitive framework with scale and variety effects. The potential dynamic gains arise once factor accumulation is allowed, leading to potential investment creation and diversion.

3 In the context of Figure 1, the distance between two countries captures the vertical difference between the natural and unnatural lines for a given $b$, and the remoteness of a pair of continental trading partners captures movement along the natural line.

Our analysis of free trade agreements is similar in some respects to the approach in Levy (1997). Levy uses a median-voter model, where all voters in a country maximize their utility and any proposal that garners a majority of voters is enacted. Levy's focus is different from ours, using the median-voter framework to address whether or not bilateralism subsequently impedes multilateralism. He adopts a twostage approach. In the first stage, voters are asked whether they prefer a bilateral free trade pact to autarky; in the second stage, voters are asked whether they prefer the existing regime (an FTA or autarky) to a multilateral free trade arrangement. Like us, Levy takes as given in the first stage that consumer welfare determines whether voters choose autarky or an FTA. One can interpret our framework as clarifying the pure economic determinants that lead consumers (and the government) in a first stage to choose between autarky and an FTA. Thus, our analysis does not preclude for future research a dynamic analysis to address the important debate of the effect of regionalism on multilateralism (cf., Freund 2000) or the effects of regional agreements inducing political pressures for nonmembers to join, such as in the domino theory of regionalism (cf., Baldwin 1994).

5 As Baldwin and Venables (1995) note, "This chapter has attempted to survey and synthesize the main contributions to this literature. Perhaps the most important conclusion to be drawn is that- despite theoretical ambiguities-RIAs (regional integration agreements) seem to have generated welfare gains for the participants, with small, but possibly negative spillovers onto the rest of the world" (1638).

6 For example, Ireland recently vetoed the accession of several Eastern European countries into the EU, presumably due to similar relative factor endowments, and the likely associated national economic impact.

7 Sapir and Winter (1994) note that "Most service sectors operate under conditions of imperfect competition resulting from various degrees of market power on the part of producers" (277).

8 The extension of the Krugman and FSW frameworks to include asymmetric countries and sectors is in the spirit of Spilimbergo and Stein (1998). Their paper attempts to consider the relative impacts of interindustry trade (generated by relative factors endowment differences) versus intraindustry trade (generated by scale and product-diversity effects). Similar to ours, they introduce two factors (capital and labor) and two sectors (agriculture and manufactures) to study the welfare implications of regional FTAs at different per capita income levels. Our model differs from theirs in several respects, some innocuous and others less innocuous. For instance, their model is structured so that one sector (agriculture) uses only labor in production. The other sector (manufactures) uses only capital; production is characterized by a simple linear cost function assuming a fixed cost and a constant marginal cost per unit of capital. In their framework, countries' factor endowments "differ only in their capital endowment" (128). Consequently, differing capital-labor ratios create differences only in per capita income through scale-economies effects, and not through traditional comparative advantages, as changes in relative-factor endowments cannot influence production shares and relative employment of capital and labor in sectors. By contrast, our model allows endogenous adjustment of capital and labor between sectors (perfect capital mobility between sectors but not between countries), and consequently can potentially separate differences between countries in per capita incomes due to scale-economies effects as well as specialization due to traditional comparative advantages. 
9 Note these transport costs are of the hub-and-spoke variety discussed in Frankel, Stein, and Wei (1995) where each continent represents a hub. For intercontinental shipments, costs are broken down into two components. The cost of transporting a good (service) from one hub to another is given by $b^{g}\left(b^{s}\right)$ and the cost to distribute the good (service) to each spoke is $a^{g}\left(a^{s}\right)$. Transportation costs of shipping goods (services) intracontinentally only consist of the cost of shipping the good from spoke-to-spoke. Note that we are ignoring at this time an important consideration for the trade of many services, namely, that the provision of some services requires the producer to come to the consumer. In our model, at present, factors are internationally immobile. We are sensitive to this constraint and intend to address this in subsequent research. To contrast our model with Krugman and FSW, for now we consider services representable by "iceberg" transport costs.

10 Asymmetries in transport costs across pairs of countries are beyond the scope of the present model.

11 Even though Goldberg and Maggi found that these implied weights were statistically significantly different from unity, they are not very different from unity economically.

12 As in Krugman (1991a), the initial optimal tariff is $1 /(\varepsilon-1)$ where $\varepsilon$ is the elasticity of demand for the country's exports. In our model, this is a function of relative economic size of the country in the world and the elasticity of substitution, $1 /(1-\theta)$. However, we want to corroborate our theoretical results with FSW. So we also compute the model using an initial tariff of 30 percent as in FSW. The theoretical results using the optimal tariff are qualitatively identical and are available upon request.

${ }_{13}$ Consider a simple two-country world: the smaller the distance between the two countries, the more they trade. Thus, the benefits from an FTA are greater.

14 As noted in Deardorff and Stern (1994), the notion of trade diversion "might seem impossible in a world of differentiated products" (57). Trade diversion, in the traditional Vinerian sense with no transport costs, describes the substitution of a low-production-cost supplier outside the FTA by a high-productioncost supplier within the FTA. However, in the model used here, there might not be "differences in production costs" (due to identical technologies and symmetric size).

One must appeal-in Deardorff and Stern's terms - to a "more general definition" of trade diversion. Even though producers here have identical production technologies, they do have different costs of supplying products due to transport costs. For instance, even though a firm on another continent may face identical production costs, the distant firm faces a competitive disadvantage from intercontinental transport costs. However, the distant firm's product will still be consumed because of the demand for variety. In equilibrium, there is a trade-off (or tension) between the demand for variety and the cost of distant products. As a natural FTA is formed, the firm on another continent faces a larger "price" disadvantage, with the amount of trade "diverted" moderated by the degree of elasticity of substitution in consumption between products.

15 To be fair, FSW (1995) noted that the results are sensitive to parameter values, noting that the net gains from a continental FTA improve with higher values for initial tariff rates and for the elasticity of substitution in consumption.

16 The simulation program is MATLAB.

17 This result is in contrast to Nitsch (1996). Like Nitsch, we find that-for a given $b$ - the welfare cost of a continental FTA decreases as a rises; however, FSW's "supernatural" region of welfare loss does not disappear. Only for higher values of $a$ (such as 0.2 - 0.4) does the supernatural effect disappear. Moreover, Nitsch found that the entire two-dimensional line shifted up. We found this result counterintuitive. At high intercontinental transport costs, there is little intercontinental trade, and so a continental FTA generates large trade creation intracontinentally relative to little trade diversion intercontinentally. Thus, higher intracontinental transport costs should, on net, reduce the trade and welfare gains from a continental FTA, counter to Nitsch's findings. Our three-dimensional figure confirms our intuition.

18 For instance, consider the case of France, Algeria, and Hungary. An unnatural (noncontinental) FTA of France with Algeria may have less trade diversion and more trade creation than a natural (continental) FTA of France with Hungary. 
19 At a very high elasticity of substitution $(\sigma=10)$, the monotonic positive relationship between net welfare gains from an FTA and intercontinental transport costs continues to hold for continental partners. However, for unnatural partners, the relationship becomes monotonic and negative.

20 This is a theoretical argument for the potential endogeneity of incomes in the subsequent empirical work. Simulations of real income confirm this.

21 As this discussion suggests, the net welfare gains (losses) from an FTA are sensitive to what other bilateral decisions are being made. That is, the net welfare gain from an FTA between country 1A and 1B is sensitive to whether country $1 \mathrm{~A}$ is considering one with (in a broader context) another country on the continent. While this issue is important, it is beyond the scope of the present theoretical analysis, which focuses on "bilateral" decisions, not multilateral ones; we leave this issue for future research. However, we do address this nonindependence of bilateral decisions empirically in a limited fashion in the econometric analysis.

22 For an excellent synopsis and three-dimensional visualization of the literature, see Haveman (1998). It is then straightforward to infer where our approach lies within the relevant literature.

23 The second traditional distinction between goods and services is that goods (services) historically have been relatively more (less) tradable. Services historically have often been regarded as "nontradables." On the other hand, recent advances in communication technology raise questions about services' relative nontradability. An exhaustive examination of the effects of greater or lesser relative services on inter- and intracontinental transport costs is beyond the scope of this paper. However, for the present section we note that higher intercontinental transport costs for services relative to goods will tend to diminish the initial level of intercontinental trade in services. Consequently, the trade-diversion effects from an FTA in this example will tend to be muted with higher relative intercontinental transport costs for services.

24 The labor economics literature, for example, often uses a labor-force participation binary variable ( 1 if working; 0 if not working) as an index of the difference in utility between working and not working; see, for instance, Mroz $(1987,778)$. In the context here, $y^{*}>0$ if two countries' representative consumers benefit from an FTA and $y^{*}<0$ if either country's welfare would decline from an FTA.

25 The 54 countries include Algeria, Egypt, Nigeria, South Africa, Hong Kong, Iran, Iraq, Japan, Singapore, Austria, Belgium, Denmark, France, Germany (W. Germany in 1960), Greece, Ireland, Italy, Netherlands, Norway, Portugal, Spain, Sweden, Switzerland, Turkey, United Kingdom, Canada, Costa Rica, El Salvador, Guatemala, Honduras, Mexico, Nicaragua, Panama, United States, Argentina, Bolivia, Brazil, Chile, Colombia, Ecuador, Paraguay, Peru, Uruguay, Venezuela, Bulgaria, Czech Republic (Czechoslovakia in 1960), Hungary, Poland, Romania, South Korea, Philippines, Thailand, Indonesia, Australia.

26 See, for instance, Frankel and Romer (1999).

27 As noted in footnote 14, the welfare gains from an FTA are influenced also by initial tariff rate levels. However, the absence of any reliable cross-sectional data for tariff rates for 54 countries precluded addressing this variable. This is left for future research.

28 We also considered a probit analysis using (instead of the inverse of distance) a binary variable representing whether or not two countries were on the same continent. The dummy variable had the correct sign and was statistically significant. However, the pseudo- $\mathrm{R}^{2}$ was nontrivially smaller in this probit regression.

${ }_{29}$ One might argue that an important omission of the determinants of the probability of an FTA between countries $i$ and $j$ is simply the bilateral trade between $i$ and $j$. In the absence of the variables we have explored, the logarithm of the average bilateral trade flow for the years 1958-1960 between the country pairs has a positive and significant effect on the probability of their having an FTA (when accompanied only by a constant); however, the pseudo- $\mathrm{R}^{2}$ value $(0.107)$ was much lower than our specifications presented in Table 1. We discuss adding this variable to specification 6 in section VI.

30 For NATURAL and REMOTE, we used the mean of the variables only for natural partners.

31 For REMOTE we used zero, and for NATURAL we used the mean of the variable only for unnatural partners. Response probabilities are not reported for REMOTE in Table $2 \mathrm{~b}$ since this variable has a value of zero here. 
32 Of these 30 cases, 7 cases involve members of the Asian Pacific Economic Cooperation (APEC) forum. While APEC is not considered an FTA, discussion has centered around members forming an FTA by 2020. Five more cases involve Panama and its five Central American neighbors. However, as noted in Frankel (1997), Panama joined the CACM as a "partial member" in 1991. Thus, in almost one-half of the 30 cases where no FTA exists, but there is a high probability of one, there are prospects for FTAs or evidence of partial FTAs.

33 We thank Francois Benaroya of the French Trade Ministry for bringing evidence about Algeria, Egypt, and Turkey to our attention. 


\section{References}

Aitken, Norman. 1973. "The Effect of the EEC and EFTA on European Trade: A Temporal Cross-Section Analysis." American Economic Review, vol. 63, no. 5, December: 881-92.

Baier, Scott L., Gerald Dwyer, and Robert Tamura. 2000. "The Growth and Development of Nations," manuscript.

Baldwin, Richard E. 1994. "The Domino Theory of Regionalism," in R. E. Baldwin, P. Haaparnata, and J. Kiander, eds., Expanding Membership of the European Union. Cambridge, UK: Cambridge University Press, 25-53.

Baldwin, Richard E., and Anthony Venables. 1995. "Regional Economic Integration," in Gene M. Grossman and Kenneth Rogoff, eds., Handbook of International Economics, Volume 3. Amsterdam: Elsevier Science, 1597-1644.

Bergsten, C. Fred. 1991. "Commentary on The Move Toward Free Trade Zones," in Policy Implications of Trade and Currency Zones, proceedings of a symposium sponsored by the Federal Reserve Bank of Kansas City, 43-58.

Bergstrand, Jeffrey H. 1992. "Real Exchange Rates, National Price Levels, and the Peace Dividend." American Economic Review, vol. 82, no. 2, May, 55-61.

. 1991. "Structural Determinants of Real Exchange Rates and National Price Levels: Some Empirical Evidence." American Economic Review, vol. 81, no. 1, March, 325-34.

. 1989. "The Generalized Gravity Equation, Monopolistic Competition, and the Factor-Proportions Theory in International Trade." Review of Economics and Statistics, vol. 71, no. 1, February, 143-53.

. 1985. "The Gravity Equation in International Trade: Some Microeconomic Foundations and Empirical Evidence." Review of Economics and Statistics, vol. 67, no. 3, August, 474-81.

Deardorff, Alan V., and Robert M. Stern. 1994. "Multilateral Trade Negotiations and Preferential Trading Arrangements," in Alan V. Deardorff and Robert M. Stern, eds., Analytical and Negotiating Issues in the Global Trading System. Ann Arbor: University of Michigan Press, 27-85.

Frankel, Jeffrey A. Regional Trading Blocs. 1997. Washington, DC: Institute for International Economics.

Frankel, Jeffrey A., and David Romer. 1999. "Does Trade Cause Growth?" American Economic Review, vol. 89, no. 3, June, 379-99. 
Frankel, Jeffrey A., Ernesto Stein, and Shang-Jin Wei. 1998. "Continental Trading Blocs: Are They Natural or Supernatural?" in Jeffrey A. Frankel, ed., The Regionalization of the World Economy. Chicago: University of Chicago Press, 91-113.

. 1996. "Regional Trading Arrangements: Natural or Supernatural?" American Economic Review, May, vol. 86, no. 2, 52-56.

. 1995. "Trading Blocs and the Americas: The Natural, the Unnatural, and the Super-Natural." Journal of Development Economics, June, vol. 47, no. 1, 61-95.

Freund, Caroline. 2000. "Different Paths to Free Trade: The Gains from Regionalism." Quarterly Journal of Economics, vol. 115, no. 4, November, 1317-41.

Gawande, Kishore, and Usree Bandyopadhyay. 2000. "Is Protection for Sale? Evidence on the Grossman-helpman Theory of Endogenous Protection." Review of Economics and Statistics, vol. 82, no. 1, February, 139-52.

Goldberg, Pinelopi Koujianou, and Giovanni Maggi. 1999. "Protection for Sale: An Empirical Investigation." American Economic Review, vol. 89, no. 5, December, $1135-55$.

Grossman, Gene M., and Elhanan Helpman. 1995. "The Politics of Free-Trade Ageements." American Economic Review, vol. 85, no. 4, September, 667-90.

. 1994. "Protection for Sale." American Economic Review, vol. 84, no. 4, September, 833-50.

Haveman, Jon. 1998. "Comment on 'The Welfare Implications of Trading Blocs among Countries with Different Endowments'," in Jeffrey A. Frankel, ed., The Regionalization of the World Economy. Chicago: University of Chicago Press, $145-49$.

. 1996. "Some Welfare Effects of Sequential Customs Union Formation." Canadian Journal of Economics, November, vol. 24, no. 4, 941-58.

Kmenta, Jan. 1997. Elements of Econometrics, Second Edition. Ann Arbor, MI: University of Michigan Press.

Kowalczyk, Carsten, and Donald Davis. 1998. "Tariff Phase-Outs: Theory and Evidence from GATT and NAFTA," in Jeffrey A. Frankel, ed., The Regionalization of the World Economy. Chicago: University of Chicago Press, 227-50.

Kravis, Irving B., and Robert E. Lipsey. 1988. National Price Levels and the Prices of Tradeables and Nontradeables. American Economic Review, vol. 78, no. 2, May, 474-78. 
. 1987. "The Assessment of National Price Levels," in Sven W. Arndt and J. David Richardson, eds., Real-financial Linkages among Open Economies, Cambridge, MA: MIT Press, 97-134.

Krugman, Paul. 1998. "Comment on 'Continental Trading Blocs: Are They Natural or Supernatural?' " in Jeffrey A. Frankel, ed., The Regionalization of the World Economy. Chicago: University of Chicago Press, 114-15.

. 1993. "Regionalism versus Multilateralism: Analytical Notes," in Jaime de Melo and Arvind Panagariya, eds., New Dimensions in Regional Integration. Cambridge, UK: Cambridge University Press, 58-89.

. 1991a. "Is Bilateralism Bad?" in Elhanan Helpman and Assaf Razin, eds., International Trade and Trade Policy. Cambridge, MA: MIT Press, 9-23.

. 1991b. "The Move Toward Free Trade Zones," in Policy Implications of Trade and Currency Zones, proceedings of a symposium sponsored by the Federal Reserve Bank of Kansas City, 7-41.

.1991c. Geography and Trade. Cambridge, MA: MIT Press.

. 1980. "Scale Economies, Product Differentiation, and the Pattern of Trade." American Economic Review, vol. 70, no. 5, December, 950-59.

Lawrence, Robert Z. 1998. "Comment on 'The Role of History in Bilateral Trade Flows' " in Jeffrey A. Frankel, ed., The Regionalization of the World Economy. Chicago: University of Chicago Press, 57-59.

1996. Regionalism, Multilateralism, and Deeper Integration. Washington, D.C.: The Brookings Institution.

Leamer, Edward E. 1998. "Comment on "The Welfare Implications of Trading Blocs among Countries with Different Endowments'," in Jeffrey A. Frankel, ed., The Regionalization of the World Economy. Chicago: University of Chicago Press, 149-51.

Lee, Jong-Wha, and Phillip Swagel. 1997. "Trade Barriers and Trade Flows across Countries and Industries." Review of Economics and Statistics, vol. 79, no. 3, August, 372-82.

Levy, Philip I. 1997. "A Political-Economic Analysis of Free-Trade Agreements." American Economic Review, vol. 87, no. 4, September, 506-19.

Linnemann, Hans. 1966. An Econometric Study of International Trade Flows. Amsterdam: North-Holland Publishing.

McCulloch, Rachel. 1988. "International Competition in Services," in Martin Feldstein, ed., The United States in the World Economy, Chicago: The University of Chicago Press. 
McFadden, Daniel. 1976. "Quantal Choice Analysis: A Survey." Annals of Economic and Social Measurement, vol. 5, no. 4, 363-90.

. 1975. "The Revealed Preferences of a Government Bureaucracy: Theory." Bell Journal of Economics, vol. 6, no. 2, 401-16.

. 1974. "Conditional Logit Analysis of Qualitative Choice Analysis," in Paul Zarembka, ed., Frontiers in Econometrics. New York: Academic Press.

Mitchell, Brian R. 1995. International Historical Statistics: Africa, Asia and Oceania 1750-1988. New York: Stockton Press.

1993. International Historical Statistics: The Americas 1750-1988. New York: Stockton Press.

. 1992. International Historical Statistics: Europe 1750-1988. New York: Stockton Press.

Mitra, Devishish. 1999. "Endogenous Lobby Formation and Endogenous Protection: A Long-Run Model of Trade Policy Determination." American Economic Review, vol. 89, no. 5, December, 1116-34.

Mroz, Thomas A. 1987. “The Sensitivity of an Empirical Model of Married Women's Hours of Work to Economic and Statistical Assumptions." Econometrica, vol. 55, no. 4, July, 765-99.

Nitsch, Volker. 1996. "Do Three Trade Blocs Minimize World Welfare?" Review of International Economics, October, vol. 4, no. 3, 355-63.

Rand McNally and Co. 1988. Road Atlas of Europe. Chicago: Rand McNally and Co.

Rivers, Douglas, and Quang H. Vuong. 1988. "Limited Information Estimators and Exogeneity Tests for Simultaneous Probit Models." Journal of Econometrics, vol. 39, 347-66.

Rodrik, Dani. 1995. "Political Economy of Trade Policy," in Gene M. Grossman and Kenneth Rogoff, eds., Handbook of International Economics, Volume 3. Amsterdam: Elsevier Science, 1457-94.

Roland-Holst, David W., Kenneth A. Reinhart, and Clinton R. Sheills. 1994. "A General Equilibrium Analysis of North American Economics Integration," in Joseph F. Francois and Clinton R. Shiells, eds., Modeling Trade Policy: Applied General Equilibrium Assessments of North American Free Trade, Cambridge, UK: Cambridge University Press.

Sapir, Andre. 1981. "Trade Benefits under the EEC Generalized System of Preferences." European Economic Review, vol. 15, 339-55. 
Sapir, Andre, and Chantal Winter. 1994. "Services Trade," in David Greenaway and L. Alan Winters, eds., Surveys in International Trade, Oxford, UK: Blackwell.

Spilimbergo, Antonio, and Ernesto Stein. 1998. "The Welfare Implications of Trading Blocs among Countries with Different Endowments," in Jeffrey A. Frankel, ed., The Regionalization of the World Economy. Chicago: University of Chicago Press, 121-45.

Trefler, Daniel. 1993. "Trade Liberalization and the Theory of Endogenous Protection: An Econometric Study of U.S. Import Policy." Journal of Political Economy, vol. 101, no. 1, February, 138-60.

U.S. Department of the Navy Oceanographic Office. 1965. Distance Between Ports. H.O. Publication No. 15, U.S. Government Printing Office.

Viner, Jacob. 1950. The Customs Union Issue. New York: Carnegie Endowment for International Peace.

Wooldridge, Jeffrey. 2000a. Introductory Econometrics. Cincinnati: South-Western Publishing. . 2000b. Econometric Analysis of Cross Section and Panel Data. Cambridge, MA: MIT Press.

World Trade Organization. 1999. Home Page (www.wto.org), November. 


\section{TABLE 1}

Probit Results for the Probability of an FTA

\begin{tabular}{|c|c|c|c|c|c|c|}
\hline \multirow[b]{2}{*}{ Variable: } & \multicolumn{6}{|c|}{ Specification: } \\
\hline & 1 & 2 & 3 & 4 & 5 & 6 \\
\hline \multirow[t]{2}{*}{ Constant } & $12.29^{*}$ & $8.44^{*}$ & 0.78 & 1.03 & 1.04 & $3.86^{*}$ \\
\hline & (20.48) & $(11.72)$ & $(0.65)$ & $(0.83)$ & $(0.83)$ & $(2.75)$ \\
\hline \multirow[t]{2}{*}{ NATURAL } & $1.60^{*}$ & $1.19^{\star}$ & $1.44^{*}$ & $1.52^{*}$ & $1.52^{*}$ & $1.61^{*}$ \\
\hline & (21.57) & $(13.81)$ & $(13.45)$ & (13.44) & $(13.46)$ & $(13.22)$ \\
\hline \multirow[t]{2}{*}{ REMOTE } & & $0.15^{\star}$ & $0.16^{*}$ & $0.17^{*}$ & $0.17^{*}$ & $0.18^{*}$ \\
\hline & & $(10.41)$ & $(10.06)$ & $(10.30)$ & $(10.25)$ & (10.03) \\
\hline \multirow[t]{2}{*}{$R G D P$} & & & $0.29^{*}$ & $0.29^{*}$ & $0.29^{*}$ & $0.25^{\star}$ \\
\hline & & & $(7.72)$ & $(7.29)$ & $(7.26)$ & (5.93) \\
\hline \multirow[t]{2}{*}{$D R G D P$} & & & $-0.26^{*}$ & $-0.29^{*}$ & $-0.29^{*}$ & $-0.34^{*}$ \\
\hline & & & $(-4.64)$ & $(-5.02)$ & $(-5.03)$ & $(-5.63)$ \\
\hline \multirow[t]{2}{*}{$D K L$} & & & & $0.36^{*}$ & 0.41 & $0.72^{*}$ \\
\hline & & & & $(4.83)$ & $(1.86)$ & $(6.77)$ \\
\hline \multirow[t]{2}{*}{$S Q D K L$} & & & & & -0.02 & \\
\hline & & & & & $(-0.27)$ & \\
\hline \multirow[t]{2}{*}{ DROWKL } & & & & & & $-1.13^{*}$ \\
\hline & & & & & & $(-5.16)$ \\
\hline \multirow{2}{*}{$\begin{array}{l}\text { Pseudo } \mathrm{R}^{2} \\
\text { Log likelihood }\end{array}$} & 0.530 & 0.606 & 0.663 & 0.679 & 0.679 & 0.700 \\
\hline & -338.3 & -283.9 & -242.8 & -231.0 & -230.9 & -216.1 \\
\hline $\begin{array}{l}\text { No. of } \\
\text { observations }\end{array}$ & 1,431 & 1,431 & 1,431 & 1,431 & 1,431 & 1,431 \\
\hline
\end{tabular}

* Denotes statistically significant z-statistic at 1 percent level in two-tailed test. 
TABLE 2

Probit Results for the Probability of an FTA for Specification 6 for Full and Subsamples

\begin{tabular}{l|r|c|c|c}
\hline Variable: & $\begin{array}{c}\text { Full } \\
\text { Sample }\end{array}$ & $\begin{array}{c}\text { Excluding } \\
\text { EU Members }\end{array}$ & $\begin{array}{c}\text { Excluding Western } \\
\text { European Countries }\end{array}$ & $\begin{array}{c}\text { Excluding All } \\
\text { European Countries }\end{array}$ \\
\hline Constant & $3.86^{*}$ & 1.70 & 0.23 & 0.81 \\
& $(2.75)$ & $(0.97)$ & $(0.14)$ & $(0.50)$ \\
NATURAL & $1.61^{*}$ & $1.04^{*}$ & $1.09^{*}$ & $1.14^{*}$ \\
& $(13.22)$ & $(7.24)$ & $(7.51)$ & $(7.06)$ \\
REMOTE & $0.18^{*}$ & $0.16^{*}$ & $0.14^{*}$ & $0.11^{*}$ \\
RGDP & $(10.03)$ & $(7.03)$ & $(6.21)$ & $(4.72)$ \\
& $0.25^{*}$ & $0.17^{*}$ & $0.23^{*}$ & $0.22^{*}$ \\
DRGDP & $(5.93)$ & $(2.94)$ & $(4.18)$ & $(3.94)$ \\
& $-0.34^{*}$ & $-0.25^{*}$ & $-0.18^{* *}$ & $-0.20^{*}$ \\
DKL & $(-5.63)$ & $(-3.30)$ & $(-2.41)$ & $(-2.69)$ \\
& $0.72^{*}$ & 0.24 & 0.14 & 0.10 \\
DROWKL & $(6.77)$ & $(1.71)$ & $(0.91)$ & $(0.61)$ \\
& $-1.13^{*}$ & $-0.78^{*}$ & $-0.71^{*}$ & -0.51 \\
Pseudo R & $(-5.16)$ & $(-2.92)$ & $(-2.64)$ & $(-1.80)$ \\
Log likelihood & -216.1 & -115.3 & -120.5 & 0.472 \\
No. of observations & 1,431 & 820 & 780 & -107.3 \\
\hline
\end{tabular}

$\left.{ }^{*}{ }^{* *}\right)$ denotes statistically significant z-statistic at 1 percent (5 percent) level in two-tailed test. 


\section{TABLE 3a}

\begin{tabular}{|c|c|c|}
\hline \multicolumn{3}{|c|}{$\mathrm{P}(\mathrm{FTA}=1 \mid$ Natural Partners $)=0.850$} \\
\hline Variable & - & + \\
\hline$N A T U R A L_{N}$ & $\begin{array}{c}0.403 \\
(0.321,0.489)\end{array}$ & $\begin{array}{c}0.990 \\
(0.975,0.996)\end{array}$ \\
\hline $\operatorname{REMOTE}_{N}$ & $\begin{array}{c}0.842 \\
(0.785,0.888)\end{array}$ & $\begin{array}{c}0.858 \\
(0.802,0.902)\end{array}$ \\
\hline$R G D P$ & $\begin{array}{c}0.701 \\
(0.612,0.780)\end{array}$ & $\begin{array}{c}0.925 \\
(0.920,0.978)\end{array}$ \\
\hline$D R G D P$ & $\begin{array}{c}0.928 \\
(0.882,0.959)\end{array}$ & $\begin{array}{c}0.730 \\
(0.642,0.886)\end{array}$ \\
\hline$D K L$ & $\begin{array}{c}0.673 \\
(0.580,0.756)\end{array}$ & $\begin{array}{c}0.947 \\
(0.905,0.972)\end{array}$ \\
\hline DROWKL & $\begin{array}{c}0.936 \\
(0.887,0.966)\end{array}$ & $\begin{array}{c}0.742 \\
(0.659,0.814)\end{array}$ \\
\hline
\end{tabular}

*Values in parentheses denote the 95 percent confidence interval for the associated response probability estimate. 
TABLE 3b

Response Probabilities to a One Standard Deviation ( $\sigma$ ) Change

in RHS Variables for Unnatural Trading Partners (Evaluated at REMOTE $=0$ )

\begin{tabular}{l|c|c}
\hline \multicolumn{3}{|c}{ P(FTA = 1|Unnatural Partners $)=0.004$} \\
\hline Variable & - & + \\
NATURAL & 0.00005 & 0.093 \\
RGDP & $(0.00001,0.0002)$ & $(0.063,0.133)$ \\
& 0.0009 & 0.014 \\
DRGDP & $(0.0003,0.003)$ & $(0.007,0.024)$ \\
& 0.014 & 0.001 \\
DKL & $(0.007,0.027)$ & $(0.0003,0.004)$ \\
& 0.0007 & 0.021 \\
DROWKL & $(0.0001,0.002)$ & $(0.011,0.038)$ \\
& 0.017 & 0.001 \\
& $(0.008,0.033)$ & $(0.0004,0.004)$ \\
\hline
\end{tabular}

"Values in parentheses denote the 95 percent confidence interval for the associated response probability estimate. 
TABLE 4

\begin{tabular}{cl||ll}
\hline \multicolumn{4}{c}{ Cases of Insufficient Bilateralism } \\
\hline Panama with & & Japan with & \\
Guatemala & $(0.641)$ & South Korea & $(0.937)$ \\
Costa Rica & $(0.971)$ & Philippines & $(0.683)$ \\
Honduras & $(0.791)$ & Indonesia & $(0.552)$ \\
Nicaragua & $(0.856)$ & South Korea with & \\
El Salvador & $(0.720)$ & Philippines & $(0.619)$ \\
Venezuela & $(0.641)$ & Romania with & \\
Mexico with & & Bulgaria & $(0.994)$ \\
Guatemala & $(0.845)$ & Hungary & $(0.893)$ \\
El Salvador & $(0.707)$ & Poland & $(0.729)$ \\
Nicaragua & $(0.574)$ & Bulgaria with & \\
Venezuela with & & Turkey & $(0.505)$ \\
Guatemala & $(0.517)$ & Switzerland with & \\
Brazil & $(0.705)$ & Algeria & $(0.877)$ \\
Peru with & & Egypt & $(0.692)$ \\
Chile & $(0.937)$ & Iran with & \\
Argentina & $(0.550)$ & Iraq & $(0.984)$ \\
Hong Kong with & & Indonesia & $(0.627)$ \\
Singapore & $(0.544)$ & Iraq with & \\
South Korea & $(0.763$ & Turkey & $(0.721)$ \\
Philippines & $(0.683)$ & Nigeria with & \\
& & South Africa & $(0.682)$ \\
\hline
\end{tabular}




\section{TABLE 5}

\section{Cases of Excessive Bilateralism}

\begin{tabular}{|c|c|c|c|}
\hline Algeria with & & Canada with & \\
\hline Denmark & $(0.371)$ & Australia & $(0.001)$ \\
\hline Germany & $(0.309)$ & Portugal with & \\
\hline Greece & $(0.489)$ & Hungary & $(0.361)$ \\
\hline Sweden & $(0.191)$ & Bulgaria & $(0.487)$ \\
\hline UK & $(0.351)$ & Romania & $(0.357)$ \\
\hline Ireland & $(0.389)$ & Sweden with & \\
\hline Egypt with & & Romania & $(0.493)$ \\
\hline UK & $(0.223)$ & Chile with & \\
\hline Belgium & $(0.325)$ & Mexico & $(0.037)$ \\
\hline Denmark & $(0.269)$ & Costa Rica & $(0.010)$ \\
\hline France & $(0.499)$ & Brazil & $(0.251)$ \\
\hline Germany & $(0.198)$ & Paraguay & $(0.255)$ \\
\hline Netherlands & $(0.335)$ & Ecuador & $(0.430)$ \\
\hline Ireland & $(0.128)$ & Mexico with & \\
\hline Portugal & $(0.088)$ & Costa Rica & $(0.488)$ \\
\hline Spain & $(0.241)$ & Bolivia & $(0.005)$ \\
\hline Sweden & $(0.167)$ & Colombia & $(0.242)$ \\
\hline Iraq & $(0.033)$ & Argentina with & \\
\hline Turkey with & & Ecuador & $(0.225)$ \\
\hline Belgium & $(0.398)$ & Bolivia with & \\
\hline Denmark & $(0.261)$ & Brazil & $(0.118)$ \\
\hline Germany & $(0.259)$ & Ecuador & $(0.273)$ \\
\hline Netherlands & $(0.409)$ & Colombia & $(0.160)$ \\
\hline UK & $(0.287)$ & Brazil with & \\
\hline Portugal & $(0.045)$ & Paraguay & $(0.240)$ \\
\hline Spain & $(0.307)$ & Philippines with & \\
\hline Sweden & $(0.251)$ & Singapore & $(0.371)$ \\
\hline Norway & $(0.127)$ & Indonesia & $(0.479)$ \\
\hline UK with & & Thailand with & \\
\hline Canada & $(0.283)$ & Indonesia & $(0.175)$ \\
\hline Australia & $(0.283)$ & & \\
\hline
\end{tabular}


Figure 1: Replication of Frankel, Stein, and Wei (1995)

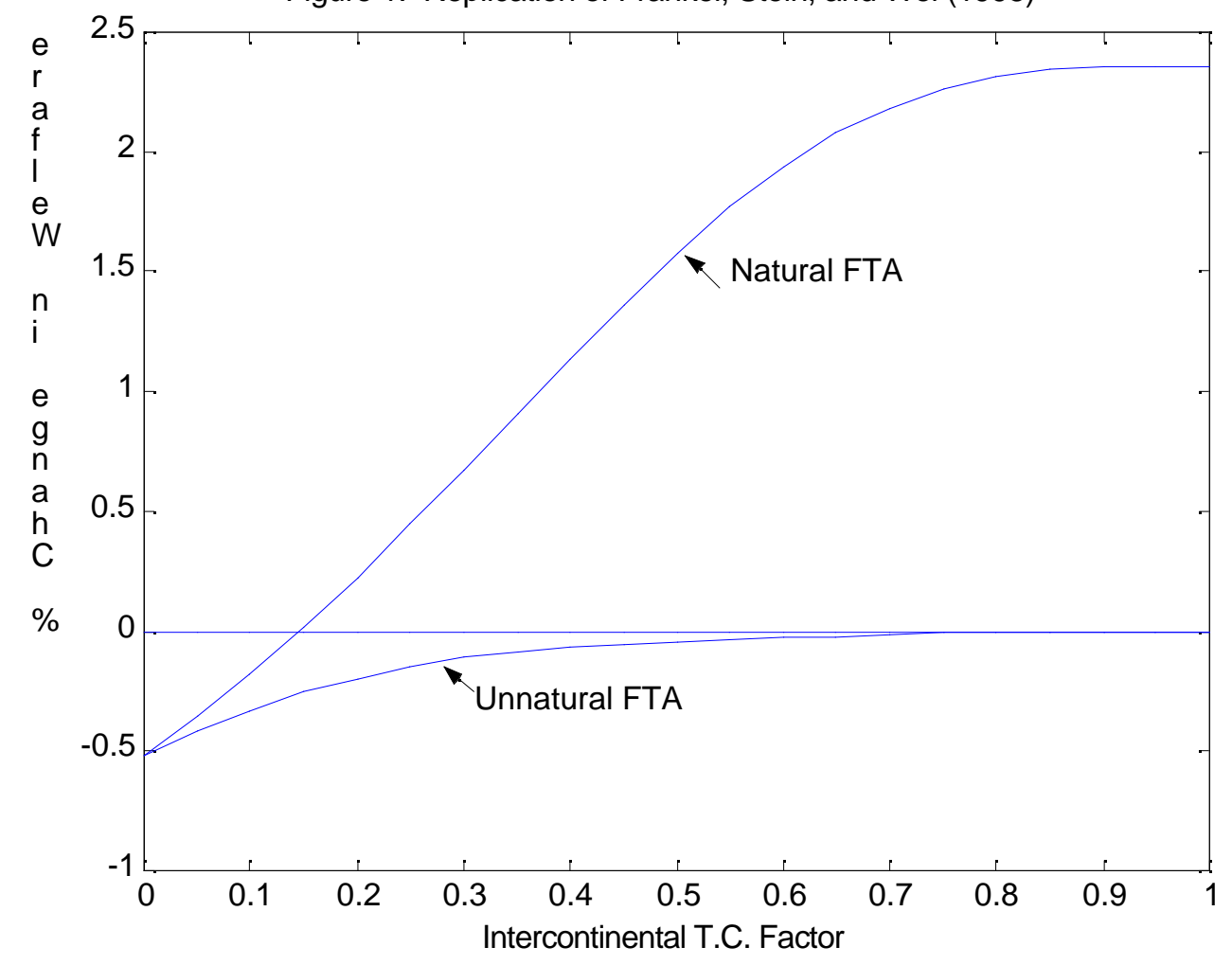


Figure 2a: Net Welfare Gains from Natural and Unnatural FTAs

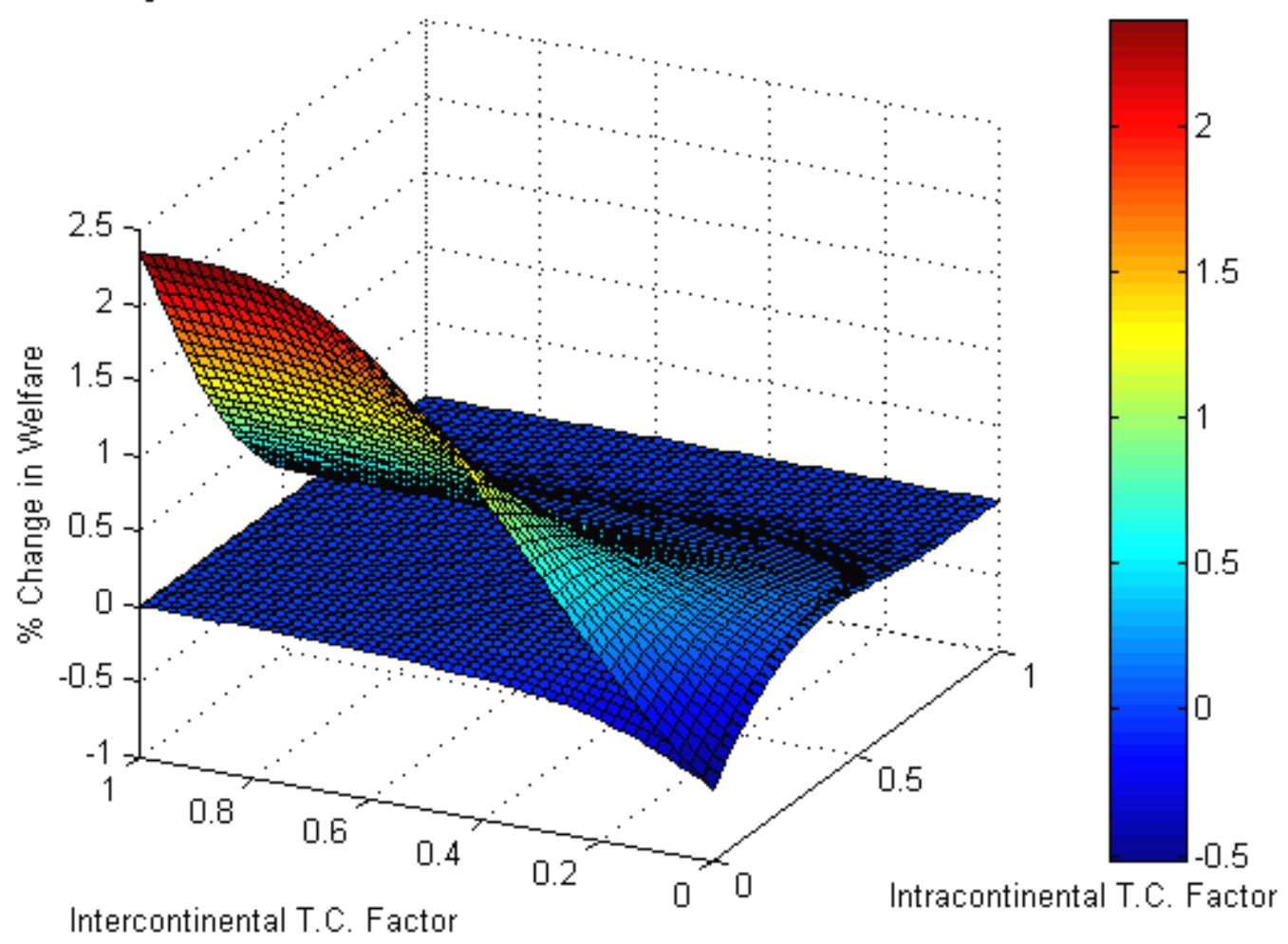


Figure 2b: Net Welfare Gains from Natural vs. Unnatural FTAs

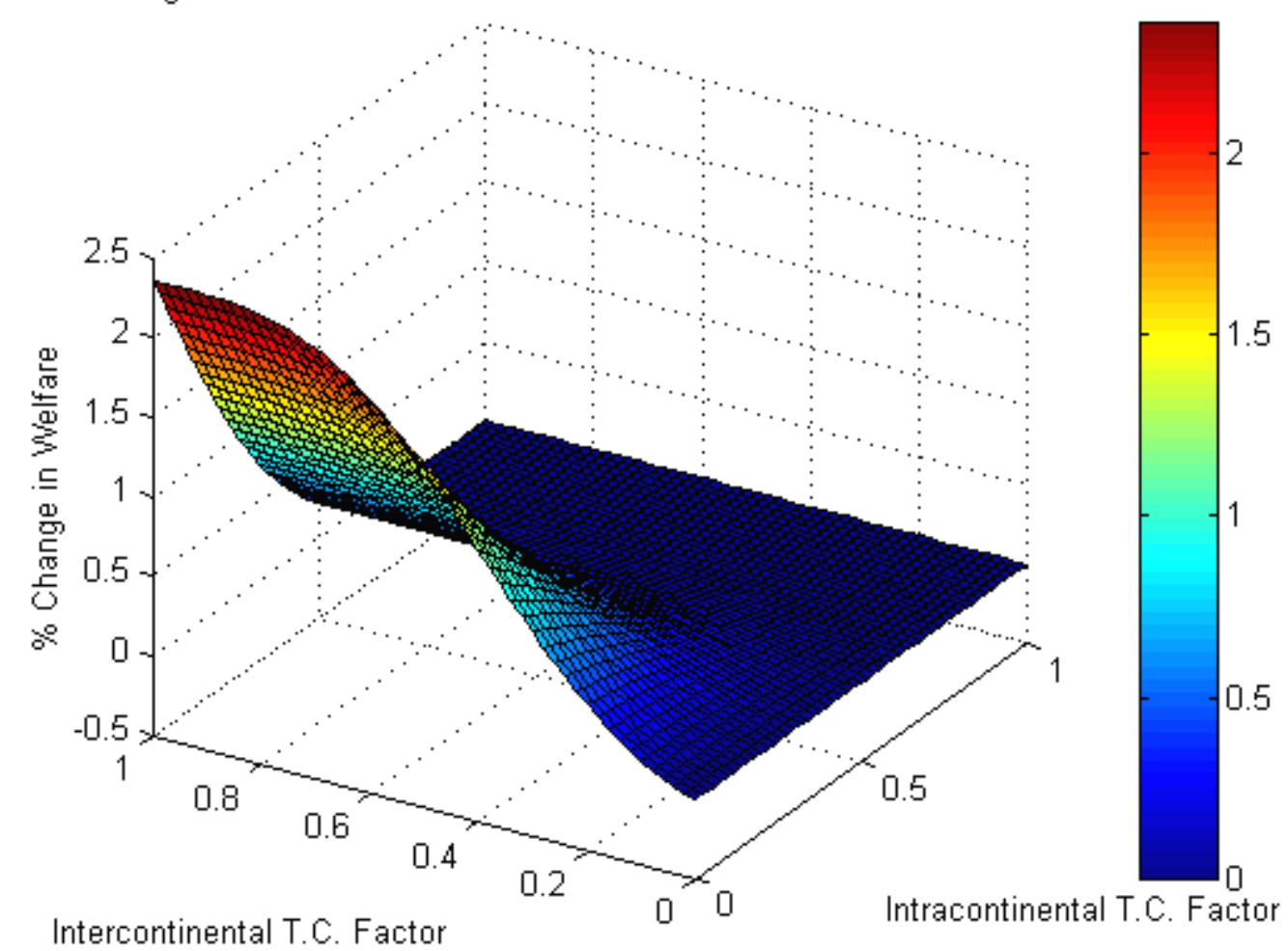


Figure 3: Net Welfare Gains from Unnatural FTAs

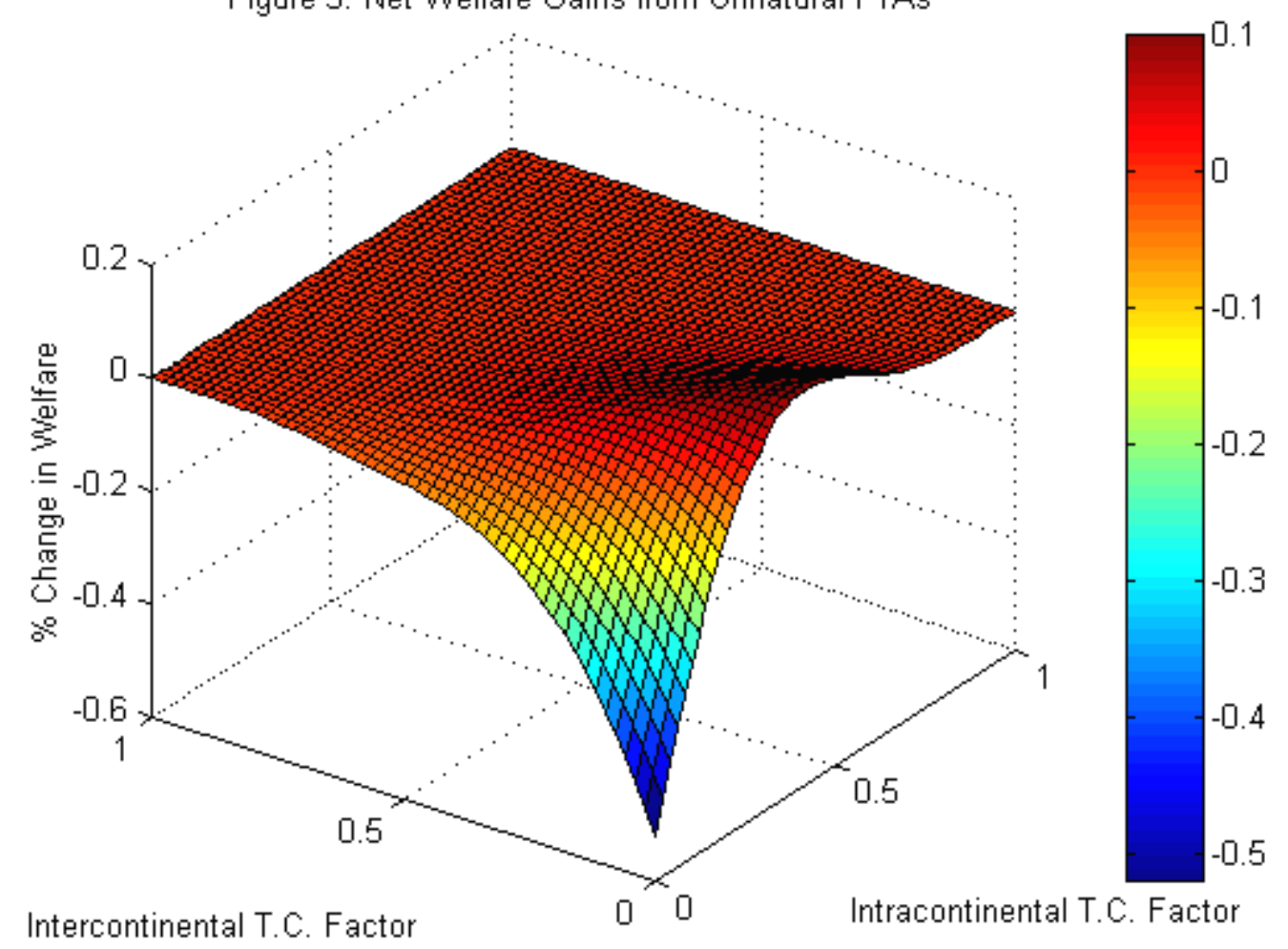


Figure 4a: Net Welfare Gains from Natural FTAs and Economic Size

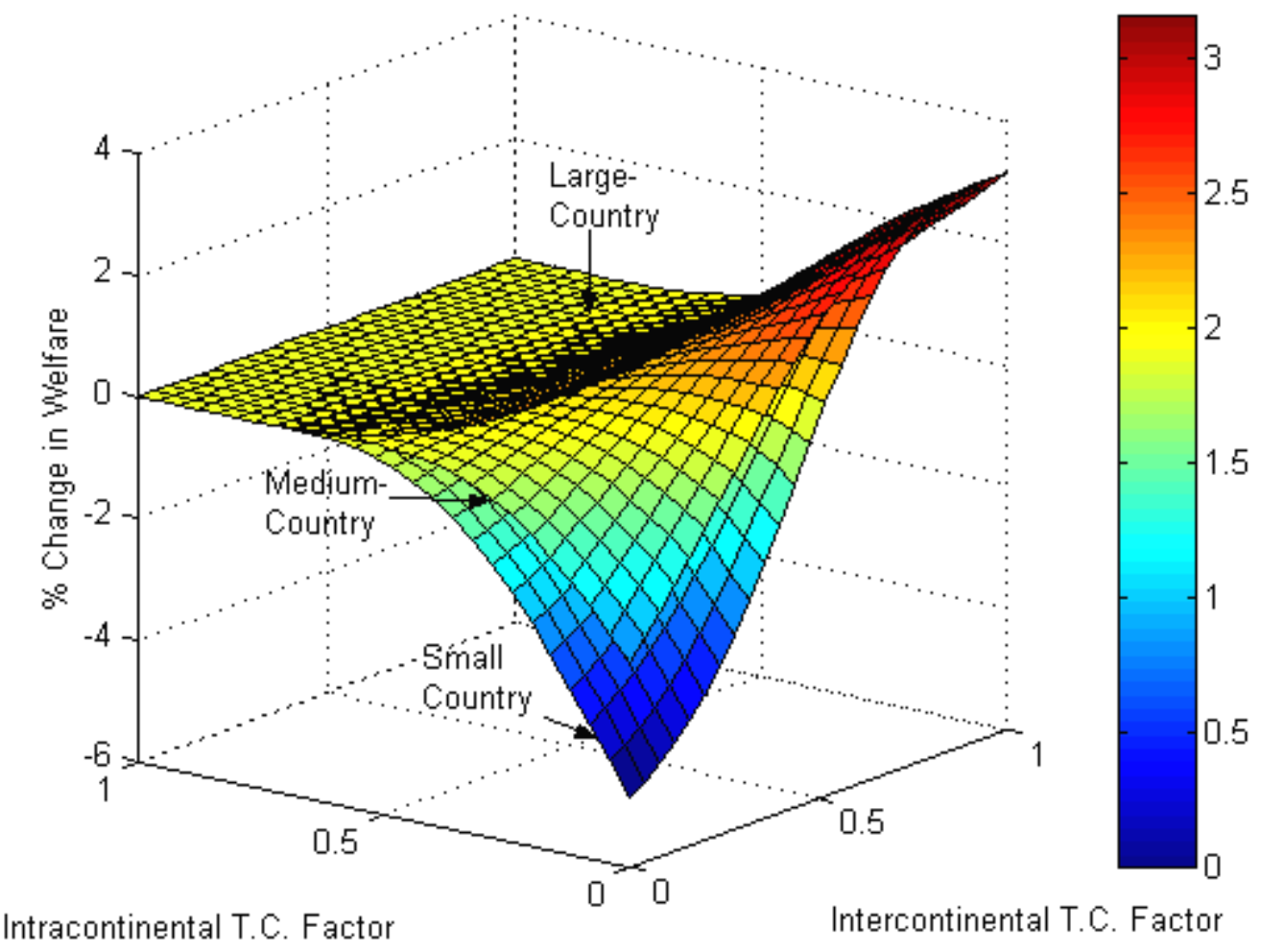


Figure 4b: Net Welfare Gains from Natural FTA and Economic Size

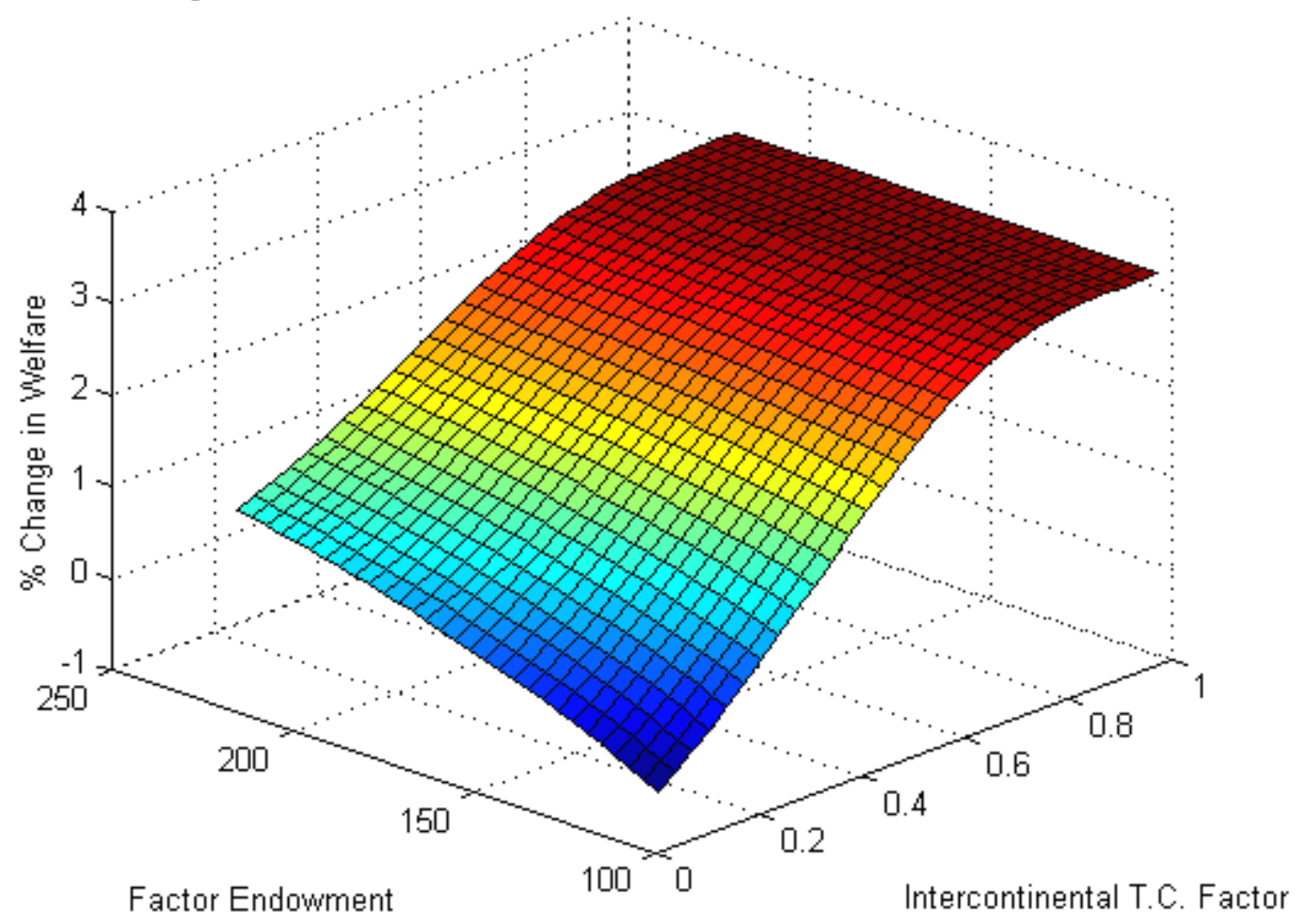


Figure 4c: Net Welfare Gains from Unnatural FTAs and Economic Size

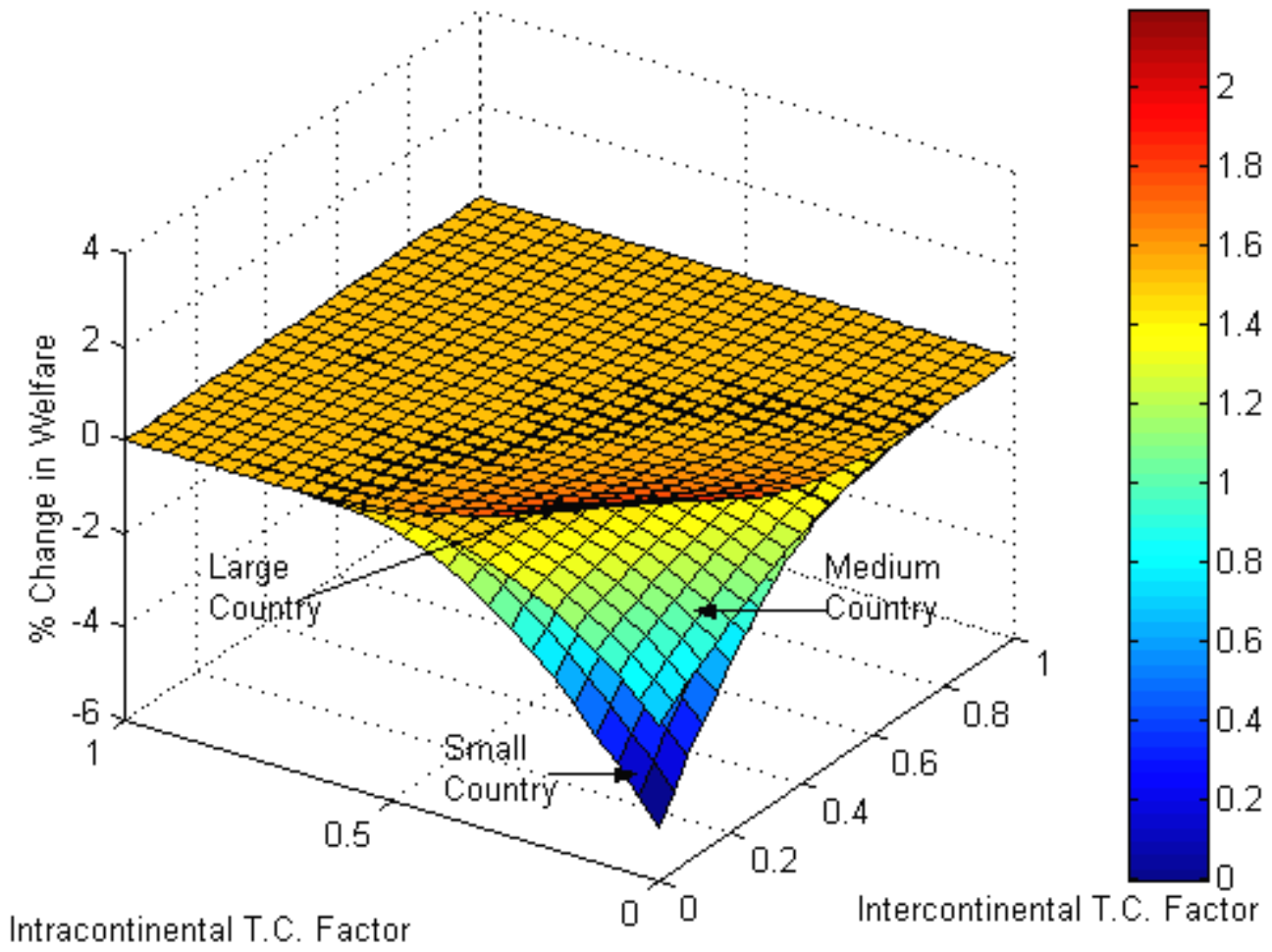


Figure 4d: Net Welfare Gains fom Unnatural FTAs and Economic Size

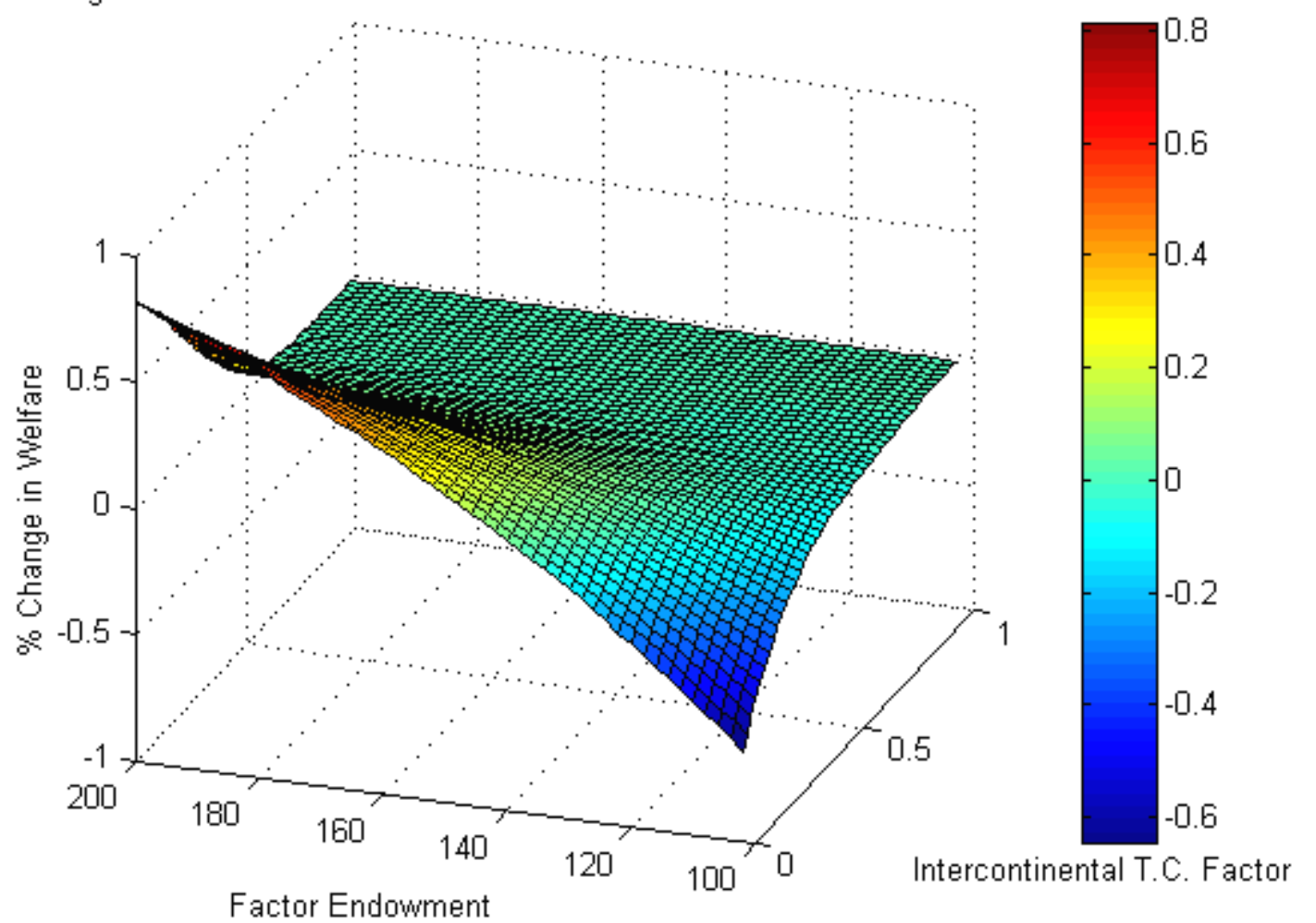


Figure 5b: Net Welfare Gains fom an Unnatural FTA and Economic Size

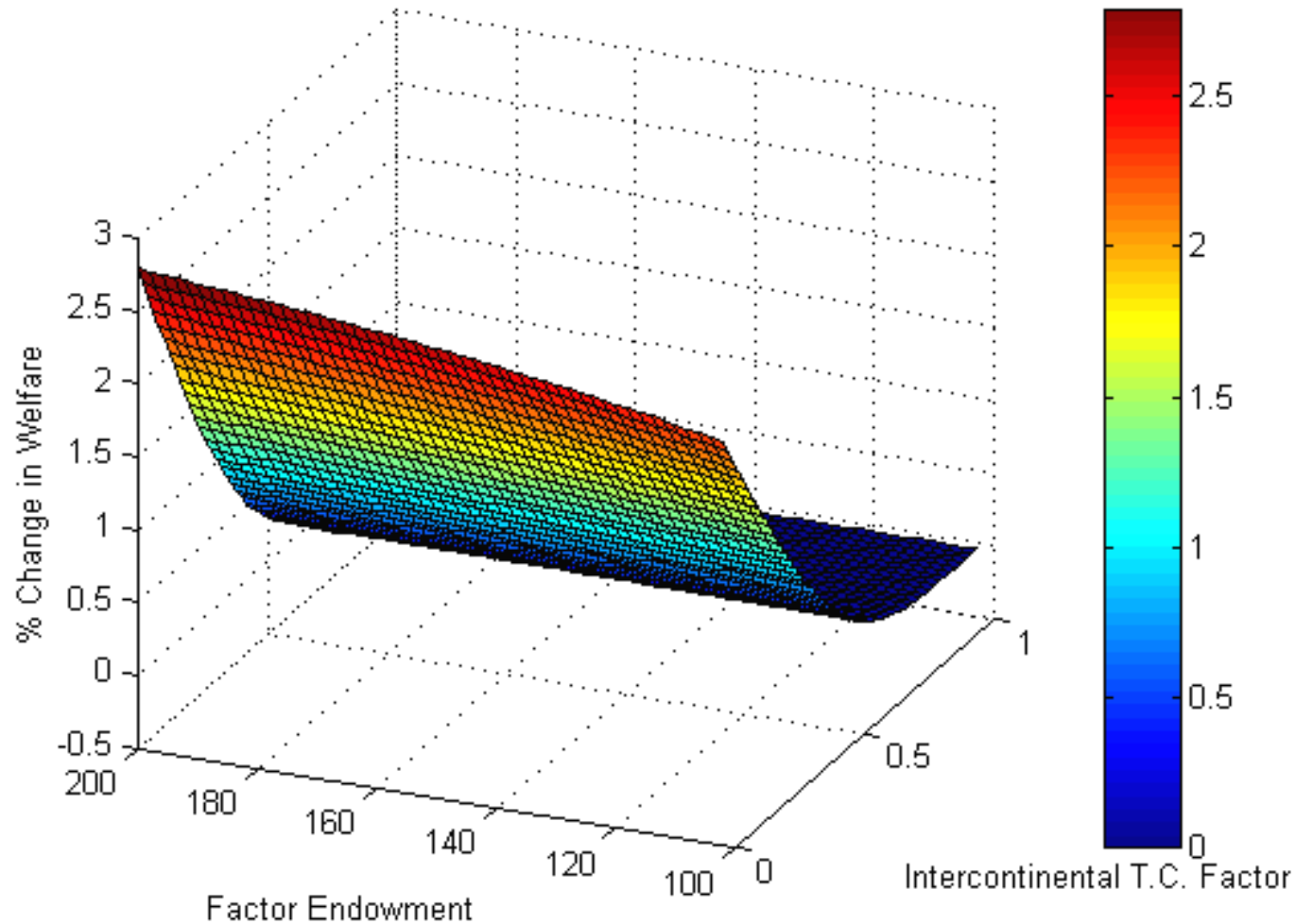


Figure 6a: Net Welfare Gains from a Natural FTA for Disparate Incomes

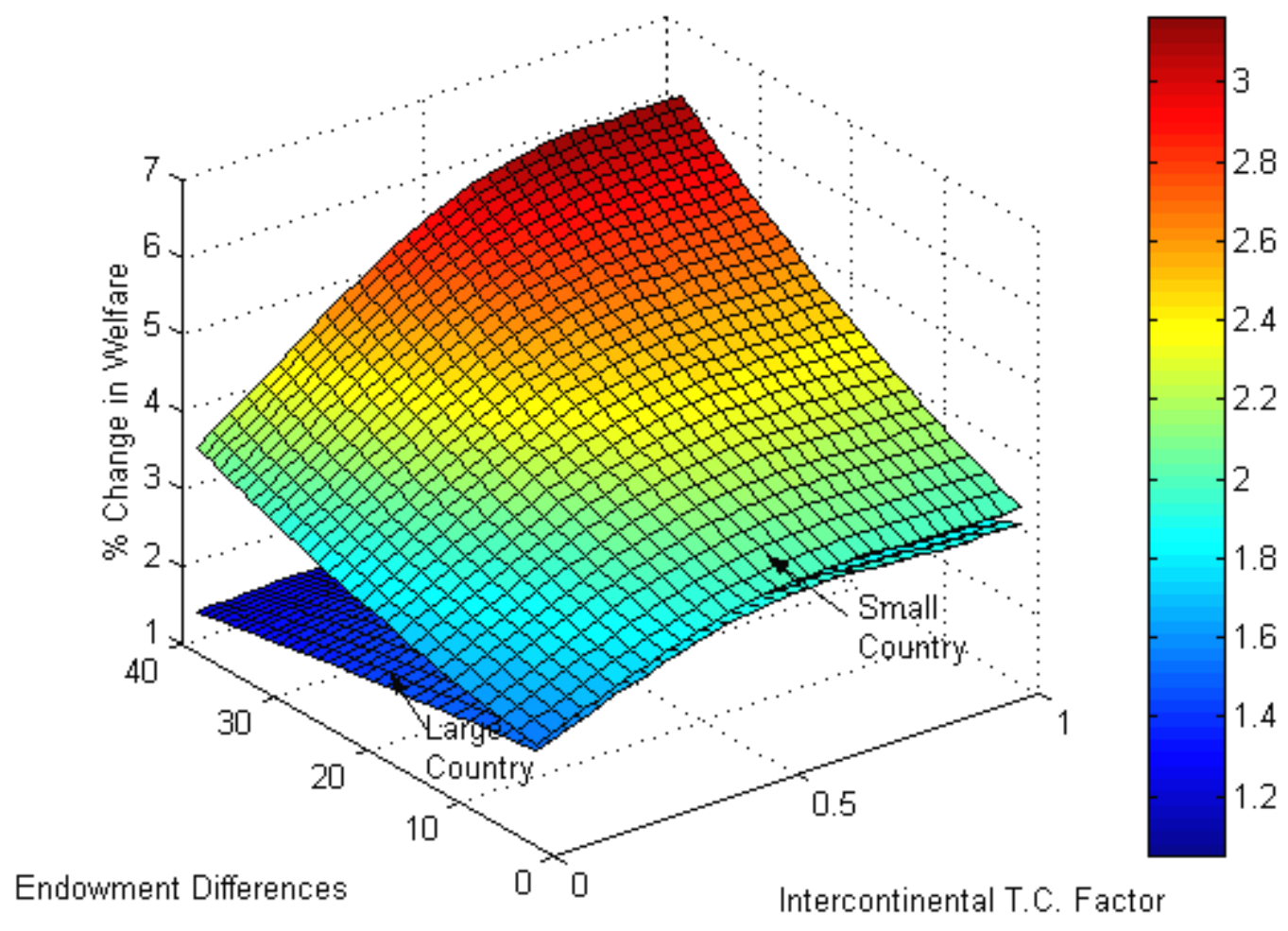


Figure 6b: Net Welfare Gains from an Unnatural FTA for Disparate Incomes

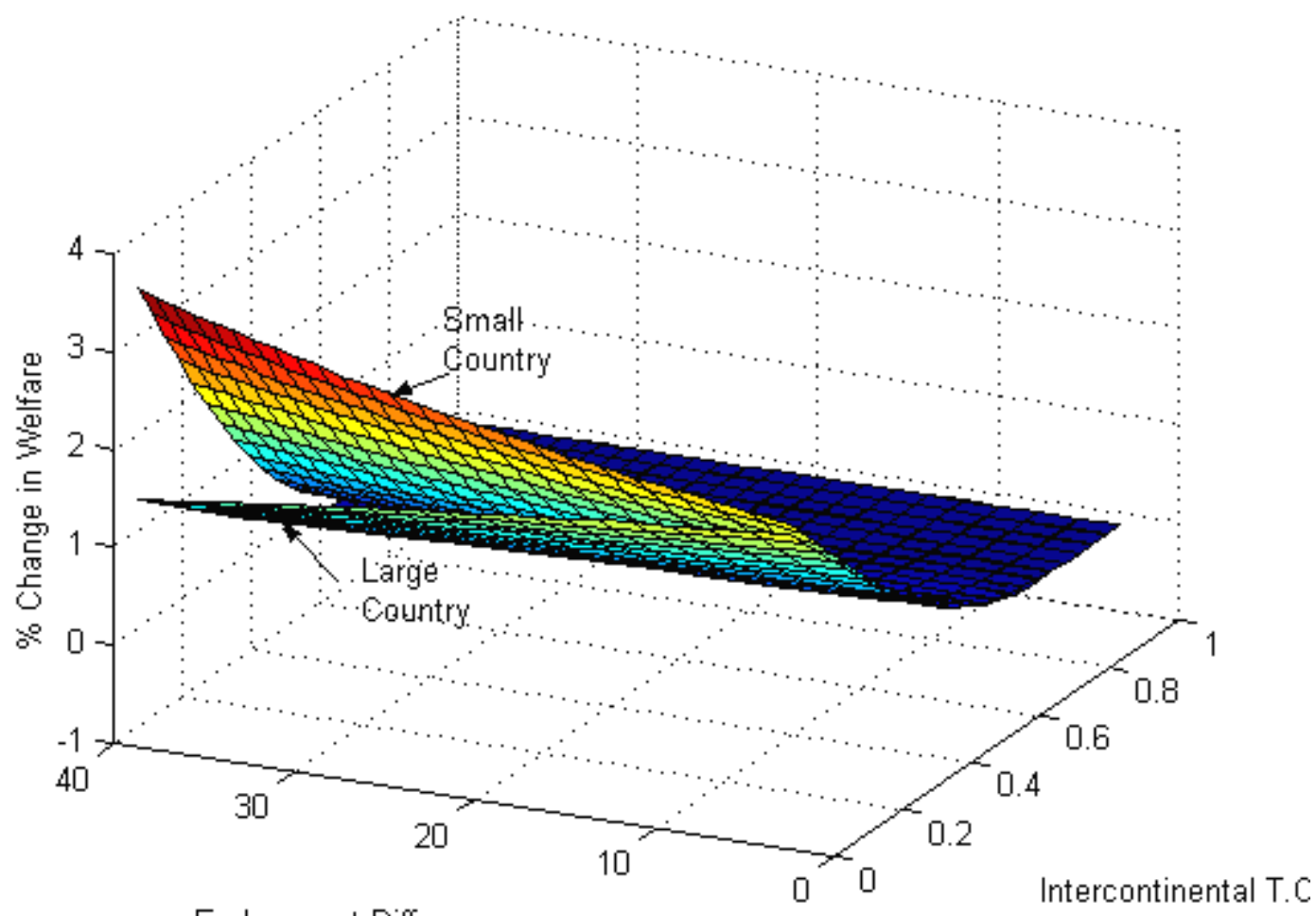

Endowment Differences 
Figure 7a: A Natural FTA and Relative Factor-Endowment Differences

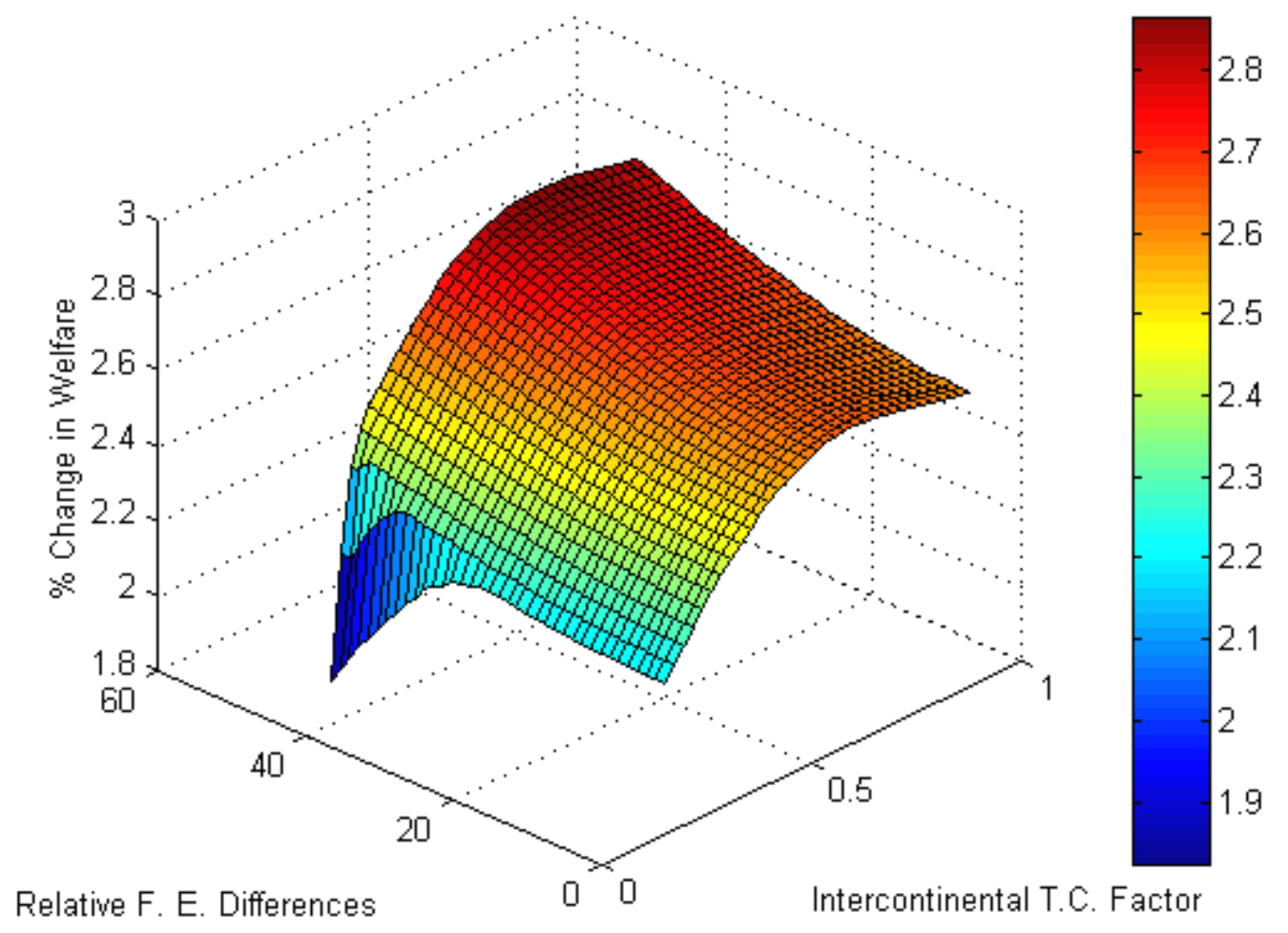


Figure $7 \mathrm{~b}$ : A Natural FTA and Relative Factor-Endowment Differences

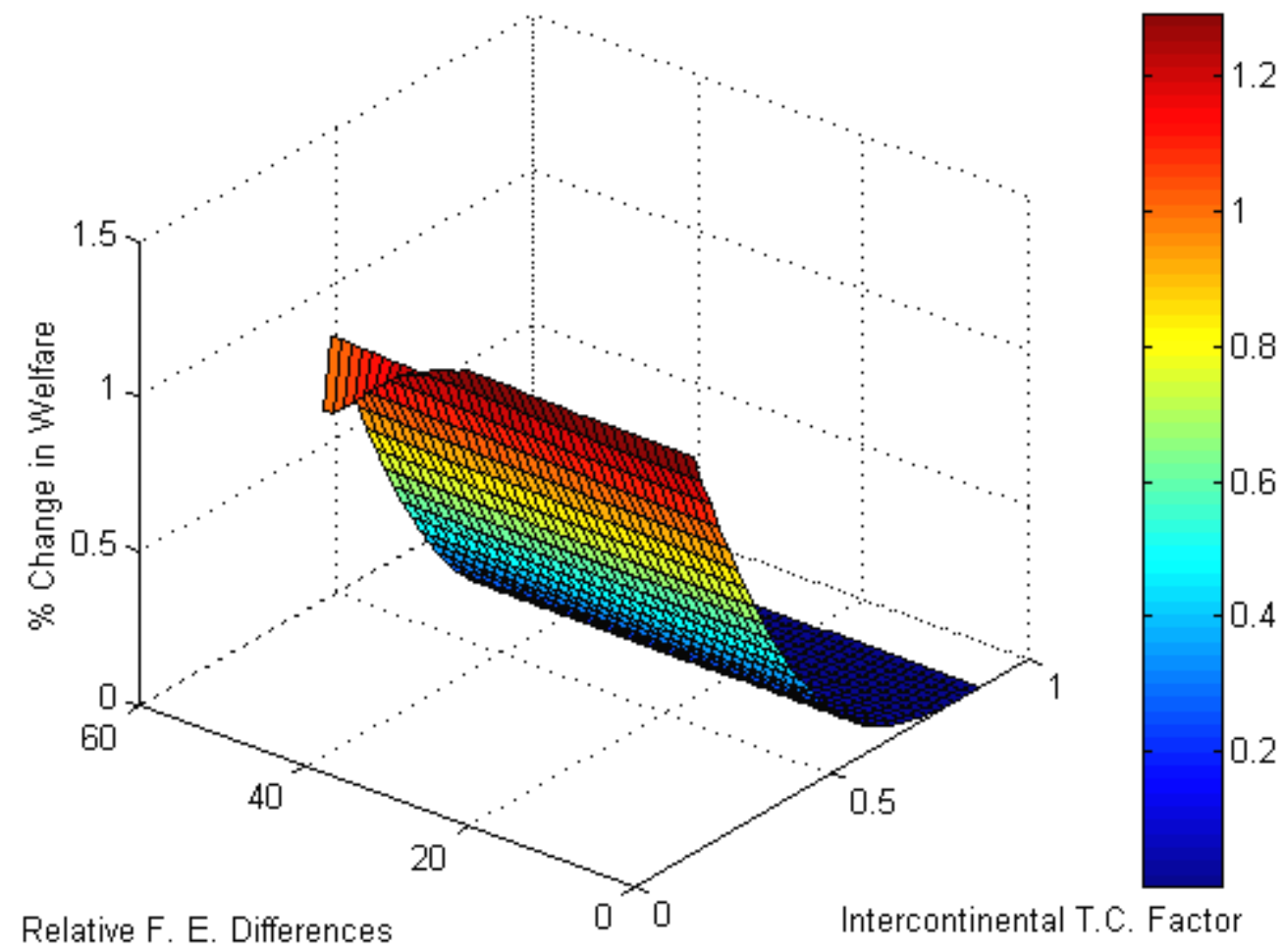

